\title{
A COMPARISON OF THE DIFFERENTIAL EFFECTS OF FOUR AVERSIVE PROCEDURES UTILIZING ELECTRIC SHOCK ON SMOKING BEHAVIOR
}

\section{By}

MICHAEL SAMUEL STOKOLS

\begin{abstract}
A DISSERTATION PRESENTED TO TIUE GRADUATE COUNCIL OF THE UNIVERSITY OF FLORIDA
\end{abstract}

LN PARTLAL FULFILIMENT OF THE REQUIREMIENTS FOR THE DEGREE OF DOCTOR OF PHILOSOPIYY 


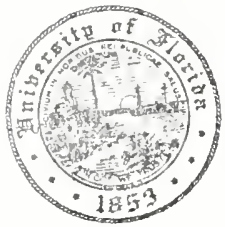

UNIVERSITY OF FLORIDA

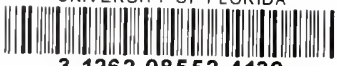

31262085524139 


\section{ACKNOWLEDGMENTS}

I would like to express my deep appreciation to the Chairman of my Dissertation Committee, Dr. William Wolking, for his encouragement; understanding, and valuable assistance during the completion of this research. I would also like to convey my thanks to the other members of my committee, Drs. Henry Pennypacker, Hugh Davis, Paul Satz, and Ellsworth Bourque, for their valuable help and advice. A special note of gratitude is also due Dr. Roy Brener, Chief, Psychology Service, and the Research Council of the Edward G. Hines Veterans Administration Hospital, Hines, Illinois, for granting me the necessary research time and facilities for the apparatus construction and data collection phases of this investigation. Finally, I would like to thank the men and women--for the most part, staff members at Hines-... who participated as subjects in this study. 
ACKNOWLEDGMENTS. • . . . . . . . . . . . . . . . $i i$

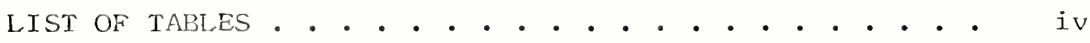

LIST OF FIGURES. • . . . . . . . . . . . . . . . V v

Chapter

I. INTRODUCTION • • • • • • • • • . • • • • 1

A Formulation of the Problem. . . . . . . . 4

Punishment and the Clinical Literature. . . 7

The Hroblem Behavior: Smoking. . . . . . 19

The Hypotheses Under Investigation. . . . . 25

II METHOD . . . . . . . . . . . . . . 30

Subjects. . . . . . . . . . . . 30

Apparatus . . . . . . . . . . . . 31

Procedures. . . . . . . . . . . . 34

ITI. RESULTS. . . . . . . . . . . . . . 45

IV. DISCUSSION . . . . . . . . . . . . . . 58

Confounding as a Function of the Procedures . 59

Situational Variables as a source of Con-

founding . . . . . . . . . . . . . 62

Some Issues for Future Research . . . . . 69

V. SUMMARY. . . . . . . . . . . . . . . 73

APPENDICES . . . . . . . . . . . . . . . . . 76

REFERENCES . . . . . . . . . . . . . . . . 81

BIOGRAPHICAL SKETCH. • . . . . . . . . . . . 87 


\section{LIST OF TABLES}

Table.

Page

1. Stimulus Items, Shock Points, and Representative

Escape Responses. . . . . . . . . . . . . . .

2. Repeated Measurements Analysis of Variance of the

MPSR Scores Across Session-Days--Groups HI, H2, and $\mathrm{H} 3 \mathrm{~N}=24$. . . . . . . . . . . . . . .

3. Neuman-Keuls Test of all Ordered Pairs of Session-

Day Means for Groups $\mathrm{H} 1, \mathrm{H} 2$, and $\mathrm{H} 3$. . . . . . 50

4. Repeated Nieasurements Analysis of Variance of the MPSR Scores Across Session-Days--Groups H1, H2, $\mathrm{H} 3$, and $\mathrm{H} 4 \mathrm{~N}=32$. . . . . . . . . . . .

5. Analysis of Variance of the MPSR Scores on the $15 \mathrm{th}$ Session-Day--Groups $\mathrm{H} 1$, H2, and $\mathrm{H} 3 \mathrm{~N}=24$. . .

6. Analysis of Variance of the MPSR Scores on the $15 \mathrm{th}$ Session-Day--Groups H1, H2, H3, and $\mathrm{H} 4 \mathrm{~N}=32$. .

7. Repeated Measurements Analysis of Variance of the MPSR Scores Two, Six, and 12 Weeks After

Treatment Termination--Groups $\mathrm{HI}, \mathrm{H} 2, \mathrm{H} 3$, and $\mathrm{H} 4$ $\mathrm{N}=32$. . . . . . . . . . . . . . . .

8. Neuman-Keuls Test of all Ordered Pairs of FollowUp Means for Groups $\mathrm{H} 1, \mathrm{H} 2, \mathrm{H} 3$, and $\mathrm{H} 4$. . . . . .

9. Analysis of Variance of Age--Groups $\mathrm{H1}, \mathrm{H} 2, \mathrm{H} 3$, and $\mathrm{H} \Lambda \quad \mathrm{N}=32$. . . . . . . . . . . . . .

10. Analysis of Variance of the Pre-Treatment Mean

Number of Cigarets Smoked per Day--Groups H1, H2, H3, and $\mathrm{H} 4 \mathrm{~N}=32$. . . . . . . . . . . . . .

11. Analysis of Variance of the Number of Years A

Cigaret Smoker--Groups $\mathrm{H} 1, \mathrm{H} 2, \mathrm{H} 3$, and $\mathrm{H} 4 \mathrm{~N}=32$.

12. Per Cent Smoking Reduction Scores Across Experimental Treatment and Follow-Up Periods--All Ss. .

13. Three-Day Means for Each S Compiled from the Actual Numbers of Cigarets Smoked Before Treatment and at the End of Follow-Up. . . . . . . . . . . . . 


\section{LIST OF FIGURES}

\section{Figure}

Page

1. H1, H2, H3, and H4 Group MPSR Scores Across the Experimental Treatment and Follow-Up Periods. . . 


\section{CHAPTER I}

\section{INTRODUCTION}

While punishment training has been the least utilized behavior the rapy method to date, a review of the recent literature does indicate that this method, of ten referred to as aversive conditioning, is finding increased favor among behavior modifiers. Nevertheless, many clinicians of varied theoretical persuasions continue to doubt the effectiveness of punishment training, viewing its use in clinical situations with serious misgivings. The reasons underlying such attitudes are numerous, and several likely ones will be mentioned here.

Before proceeding, however, a definition of punishment, as it pertains to this study, is in order. Punishment, then, has been defined as: (1) some physically aversive or noxious stimulus which is either contiguous with a CS, or contingent upon the performance of some behavior (Church, 1963); and (2) a stimulus which a subject (ㅇ) will reject if given a choice between it and no stimulus at all (Solomon, 1964). Thus, such procedures as, e.g., verbal disapproval, restraint, the withholding of positive reinforcement, time-outs, or massed practice, while they may properly fall under the general rubric of negative reinforcement, will not be considered punishment in this narrower sense. 
As Solomon (1964) has pointed out, a large number of clinicians undoubtedly feel that punishment just does not work; that its effects are transient, unstable, inconsistent, and do not really weaken habits. The the rapist who has $h$ is doubts about the effectiveness of punishment is in good company. Many prominent psychologists have disavowed punishment as having any lasting suppressive effects on behavior (e.g., Bandura, 1962; Estes, 1944; Skinner, 1948, 1953; Thorndike, 1932). Many writers and editors of texts dealing with the areas of learning and conditioning devote but a few Iines to the problem of punishment (e.g., HuIl, 1951; Kimble, 1961; Woodworth and Schlosberg, 1958). Solomon points out that many contemporary introductory psychology texts devote scant space to punishment as a scientific problem, citing as a case in point George Miller's recent text, Psychology, the Science of Mental Life, which contains no discussion of punishment anywhere.

The state of the experimental learning Iiterature is in itself most confusing, and undoubtedly contributes in no small measure to the negative feelings many clinicians hold towards the use of punishment in cIinical situations. While much experimental evidence indicates that punishment decreases the probability of a response occurring, contrary experimental results, often referred to as "paradoxical efrects," are legion (refer to articles by Church, 1963; Kushner and Sandler, 1966; Martin, 1963; Sandler, 1964; and Solomon, 1964). For example, several studies have shown that when punishment is correlated with positive reinforcement during acquisition trials, punishment- 
extinction trials produce an increase in responding over con ditions of regular extinction; also, there is usually increased resistance to extinction (Carlsmith, mentioned by Solomon, 1964; Holz and Azrin, 1961, 1962; Martin ano Ross, 1964). Karsh (1.962) found that punishment, if introduced before the asymptotic performance under regular training has been reached, may well induce further improvement under the punishment procedure. Azrin (1959, 1960) found that when mild punishment of an instrumental response acquired under positive reinforcement is terminated, there is often a temporary increase in response rate over that which would have occurred without punishment. Several researchers have reported that increased learning in selective learning situations often obtains when "right" responses are punished (Muenzinger et al., 1938; Muenzinger and Powloski, 1951; Prince, 1956). And, there have been studies showing that, under certain conditions, Ss prefer continued exposure to punishment, even though non-punishing alternatives are available (Brown et al., 1964; Sandler, 1964). While many more examples could be given, perhaps Church (1963) best sunmed up the "paradoxical" literature with his observation that punishment, under particular circumstances, might result in almost any conceivable effect.

Solomon (1964) also suggests that the fear of unwanted emotional side effects, often produced in the laboratory, has probably deterred many therapists from making use of punishment procedures. Many animal studies have, in fact, produced highly disturbed $\underline{S}$ (e.g., Brady's [1958] work with ulcerous 
monkeys; Gantt's [1944] work with neurotic dogs; Maier's [1949] work with fixated rats; Masserman's [1943] work with neurotic cats and monkeys; and Masserman and Pectel's [1953] work with monkeys). Among others, such factors as high stimulus intensities, the punishment of consummatory and instinctive behavior, punishment under non-discriminatory control, the unavoidability of punishment, and the punishment of responses acquired under negative reinforcement all seem to contribute towards such results.

Finally, but perhaps most importantly, the often ambiguous and inconclusive results of many of the published clinical studies and case reports using punishment as the treatment variable have, in all probability, discouraged many therapists from making use of punishment training procedures. Before turning to relevant examples of this literature, however, the major focus of this study will first be considered.

\section{A Formulation of the Problem}

In the majority of the clinical cases which have utilized a punishment paradigm, the major underlying assumption seems to have been the rollowing: that the simple pairing of a short-duration noxious stimulus with either a presenting stimulus (the CS) or an elicited response would be sufficient to insure the subsequent lasting suppression of the target behavior in question. While the emphasis seems to have been focused on the problem of obtaining response suppression -n i.e., getting the patient not to do something -- relatively 
little experimental literature is available concerning the problem facing the clinician of systematically getting the patient to do something else instead. This issue is certainly familiar to the laboratory investigator studying escape and avoidance learning. In such experiments the design usually provides for the development of alternative instrumental escape and avoidance behaviors as a way of averting or attenuating the noxious stimulus.

Solomon (1964) has stated: "Punishment becomes extremely effective when the response-suppression period is tactically used as an aid to the reinforcement of new responses that are topographically incompatible with the punished one" (p. 24I). One way to achieve this end would be to use the noxious stimulus itself as a reinforcer for new behavior judged to be incompatible with the punished response. If cessation of shock is made contingent upon the occurrence of an operant, this escape response will be reinforced. Soon, escape and then avoidance responses should be occurring in stable fashion immediately upon presentation of the stimulus pattern(s) which formerly elicited the punished response. Mowrer (1960) calls such learning "active avoidance learning" and presents several examples illustrating this paradigm in his book, Learning Theory and Behavior.

Turner and Solomon (1962) using human Ss, and electric shock as the UCS, showed the effectiveness of making cessation of long-duration shock contingent upon deliberate, 
voluntary operants (as opposed to short-latency reflexive re.sponses) for escape and avoidance learning. of course, the behavior therapist is primarily concerned with the suppression of unwanted behavior, and Turner and Solomon did not concern themselves with response suppression, per se, in their monograph. However, it could reasonably be expected that by combining in treatment what the behavior therapist employing punishment training attempts to do -- that is, foster response inhibition as a result of the negative conditioned emotional response which develops when punishment is made contingent upon a response - with what Solomon (1964) suggests be done -- that is, sequentially reinforce an operant response incompatible with the punished response -- far more effective and longer lasting response suppression should occur.

While this procedure is well known in the experimental literature, many clinicians have either ignored such an approach, or have made relatively little systematic use of this tactic in their treatment of patients. This has been especially true in the many instances where drugs have been employed as the averssive stimulus. A major intent of this study, then, will be the attempt to demonstrate clinically whether a long-duration noxious stimulus employed in the manner suggested above would, in fact, be more effective in inducing lasting response suppression than the same stimulus of short duration simply paired with the target response, or the $\mathrm{CS}(\mathrm{s})$ eliciting such behavior. And, the experimental learning and conditioning findings have also overwhelmingly indicated that non-contingent or randomiy 
administered stimuli - - either positive or negative -- have little lasting suppressive or facilitative effects on behavior. All clinical attempts utilizing aversive conditioning methods have at least assumed this much in the design of the treatment procedures. To this end, then, the attempt to demonstrate that a short-duration noxious stimulus presented randomly would not have any lasting suppressive effect on a given response pattern, will also be made. The results of such a demonstration should establish a more meaningful base from which to view the data obtained from the above mentioned comparison.

Punishment and the Clinical Literature

Choice of the Noxious Stimulus

By far, the majority of the published aversive conditioning studies have concerned themselves with the treatment of alcoholism and the sexual deviations. In most cases the aversive stimulus has been an emetic drug such as apomorphine or enetine, and, by and large, conditicning principles have been violated in many instances (Eysenck, 1963; Franks, 1958, 1963; Rachman, 1965). Apparently some clinicians have given the patient alcohol (the CS) after the paijent reached the height of nausea (backward conditioning), time intervals between presentation of the various stimuli have not been controlled, and the nausea-inducing drugs may have acted as central deprossants, thereby possibly interfering with the acquisition of the conditioned responses (Eysenck and Pachman, 1965). Others have focused on the act of vomiting rather than the feeling of nausea as the CS, and individual reactivity to the drugs has been a 
confounding factor (Barker et a1., 1961).

Sanderson (1963) rotes that the reaction to apomor.-

phine is too gradual and too irregular to meet the requirements of a good UCS. Also, the use of emetic drugs as aversive stimuli is: (1) cumbersome and messy; (2) involves undue man-hours, expense, and effort; and (3) often necessitates the taking of exacting medical precautions including hospitalization to insure the safety of the patient (Rachman, 1965). Cases in point are the studies of Clark (1963), who treated a case of fetishism; Sanderson et al., who treated alcoholics (reported in Franks, 1964); Raymond (1956), who treated a case of handbag fetishism and perambulator destruction; Cooper (1963), who treated a case of inpotence and fetishism; and Barker (1965) and Barker et al. (1961), who treated cases of transvestism. Cooper's paper in particular dramatically points out the degree to which patients undergoing this kind of treatment are physically debilitated, fatigued, and endangered.

Thus, in this study, electric shock was used as the noxious stimulus of choice. Not only can electrical stimulation be more precisely controlled, it can be delivered at a determined intensity for an exact duration of time at precisely the required moment. And, not only does electric stimulation avoid many of the disadvantages of the emetics listed above, it has the added advantages of not requiring medical supervision nor more than one person in its administration (Barker, 1965; McGuire and Vallance, 1964; Rachman, 1965). Further, from the 
personal clinical experience of E with this method, and from ex-perience directly related to this study, it has been observed that, while most patients or Ss have not liked the experience of getting shocked, none exhibited intense fear reactions or immobilization to the procedure. And, lastly, the vast majority of the studies in the experimental punishment literature have used electric shock as the aversive stimulus, thus providing the clinician with a wealth of potentially valuable experimental data. Thus, only aversive conditioning studies which have employed shock as the noxious stimulus will be mentioned here. Clinical Studies Using Electric Shock

Thorpe et al. (1963) administered shock to a homosexual patient through a grid on the floor after two non-aversive procedures with the same patient had failed to bring about any change in his behavior. Using a VI/VR reinforcenent schedule, shock, presumably of short duration, closely followed the illumination of a photograph of a nude male on approximately one quarter of the presentations. The patient received a total of 100 trials, each consisting of 40 illuminations. Follow-up apparently showed that, at best, the patient could be considered bisexual rather than exclusively homosexual. Using essentially the same procedure with another homosexual, Thorpe and Schmidt (1963) reported in the same volume that the patient terminated treatment after three sessions over two days. This case was deemed a failure.

McGuire and Vallance (1964), also following a simple punishment model, reported treating cases involving fetishism, 
smoking, writer's cramp obsessional ruminations, and alcoholism. They indicated that just over 50 per cent of these patients $(N=39)$ improved sufficiently to receive a "good improvenent" or "symptom removed" rating at the end of treatment. Apparently, the authors encouraged their patients to administer their own shock, both during treatment sessions and at home.

Mees (1966) recently reported in great detail the treatment of a case of sadistic fantasies in a 19-year-old male. After 25 weeks of baseline data collection, short-duration shock was delivered to the fingers when the patient imagined selected parts of his fantasy. Over 6,000 shocks during 65 sessions were given during the 14-week treatment period. Follow-up 11 weeks later indicated that the patient's sadistic fantasies accompanying masturbation had markedly decreased and that heterosexual fantasies were increasing. Like the patients of McGuire and Vallance above, Mees' patient began shocking injself during the second week of punishment training, sometimes for periods up to two hours. Wolpe (1965) also reported that a physician with drug addiction of three years' standing was able to "significantly reduce" his cravings with only nine "distinctly strong" shocks which were self-administered over approximately a three-week period. Three months later, however, there was a complete relapse and arug taking resumed unabated. Feldman (1966) criticizes the procedure of allowing the subject to shock himself on the grounds that punishment may become sought after; i.e., may become positively reinforcing, especially 
if the patient is free to set his own intensity level.

Sandler's (1964) concept of masochism, defined as the situation in which a noxious stimulus does not result in avoidance behavior being exhibited by the $\underline{s}$ receiving it, might also be relevant here.

Kushner (1965), and Kushner and Sandler (1966), refer to a fetishist who was treated along simple punishment lines, for the rnost part. Shock of short duration was paired with the patient's images of himself engaging in various aspects of his fetishist activity, presentation of the fetishist object (woman's panties), and the presentation of a sexually arousing picture. An 18-month follow-up showed the patient to be essentially free of his fetishist behavior. The latter stlidy (Kushnex and Sandler, 1966) also reported the treatment of an obsessive suicidal ruminator, an occupational compulsive hand contractor, and an exhibitionist with short-duration shock. Follow-up (12 months) indicated complete suppression of the exhibitionist activity, moderate success in the case of the suicidal ruminator (three-month follow-up), and little if any improvement on the job after 101 shock sessions for the hand contractor. The last-mentioned patient's teletypewriter performance was much improved during treatment sessions, however. Thorpe et al. (1964) used a technique which they called "aversion relief therapy" in treating three "homosexuals" (two were called latent), one fetishist, one phobic, one obsessivecompulsive, and one depressive compulsive eater. Using 24 
words on a disc appropriate to each patient's problem as the CSs, they presented each word in turn, pairing it with short-duration shock to the feet. The last word-- e.g., in the case of a homosexual it might be "heterosexual" -- was not shocked and thus was the "relief" word, as it signaled the end of the trial. While results of this study were ambiguous as presented, all the patients seened to be improved to some degree immediately following treatment, with the exception of the obsessive-compulsive and the compulsive overeater. Both of these patients terminated treatment. Since only very brief follow-ups were given, little can be said about the efficacy of this particular brand of punishment training.

Meyer and Crisp (1964) reported treating two obese women with shock, but the exact procedures are anything but clear. Certain foods were displayed in the same room with the patient, and shock was contingent upon actual movement by the patient towards the "temptation" food. The shocks ceased when the patient ceased moving towards the food, and apparently could be avoided entirely during any given session. The authors report one success and one failure but leave unanswered questions pertaining to, e.g., shock duration and number, whether the reinforcement contingency was completely controlled by the $\underline{S}$, whether gross movement toward the "temptation" food was the only experimental response focused on, or how much time the patients spent in the treatment rooms.

Through the use of short-duration response-contingent shock (onset sometimes delayed up to 30 seconds, though) Tate 
and Baroff (1966) deconditioned acute self-injurious behavior (SIB) in a hospitalized psychotic boy over a period of five months. Eventually, just the threat of shock was sufficient to produce a reduction in other unwanted behavior such as posturing and not eating. Withdrawal of physical contact ("timeout") was previously used as the negative reinforcement, but shock was found to be far more effective in suppressing the unwanted behavior. The authors refer to a paper read by Lovaas et al., and a personal communication by Ball, all of whom used similar shock procedures to successfully suppress SIB in several schizophrenic children and a severely retarded girl, respectively.

Bancroft et al. (1966) recently reported treating a pedophiliac with electric shock over a 38-day period. Briefly, the patient was told to concentrate on sexually stimulating fantasies after viewing pictures of children. When an erectile response occurred, which registered on a specially constructed transducer, shock was administered to his arm. Once in every four trials, the shock box was disconnected, and the patient was given pictures of adult women and encouraged to produce an erection with heterosexual fantasies. After an 18-month follow-up period, the patient continued to display a variety of sexual difficulties although pedophilia was no longer the major problem.

Hsu (1965) placed a tray containing six one-ounce plastic cups filled with beer, wine, whiskey, milk, water, and fruit juice in front of alcoholic patients, and then as 
each alcoholic drink was swallowed, an electric shock, 30 seconds in duration, was administered. After completion of the five-day treatment sequence, the patient was released from the hospital with the provision that he return for twoday booster treatments at four-week and six-month intervals. The results of this treatment procedure were ambiguous. First, Hsu used "out of the hospital working or seeking employment" as the criterion measure for treatment effectiveness, not the decrease or absence of further drinking behavior. Secondly, Hsu failed to provide clear-cut follow-up data. It was simply reported that of 40 patients who received treatment, 20 failed to complete the initial five-day sequence or the first reinforcement booster treatment. The other 20 patients did at least get that far, and of these, 13 were simply described as being "out of the hospital working or seeking employment." There were other puzzling aspects to this study. Hsu's placement of the electrodes above both ears of his patients was, to say the least, atypical and wi thout precedent or subsequent imitation in the recent aversive conditioning literature. The patients' reactions to the shock stimulus were also atypically severe. Many patients exhibited marked physical responses such as foot stamping, hand trembling, crying and screaming, nausea and vomiting. Others reported feeling head pain and seeing "flashing 1ights." Finally, the duration of the shock -- 30 seconds - - was not explained on theoretical or empirical grounds, and shock cessation was not contingent upon any particular response or stimulus event. 
Very few of the aversive procedures cited in the foregoing case reports have seemed to be rooted very deeply or systematically in the general body of the experimental psychology of learning. Certainly none of these papers systematically provided for the development of alternative and more desirable escape and avoidance behavior by utilizing the positive reinforcing effects of response-contingent shock cessation. Several studies employing shock as the noxious stimulus have, however, evidenced their greater awareness of these procedural considerations, and to these attention will now be turned.

Blake (1965), working with some 50 to 60 fee-paying alcoholics, has atterpted to test the efficacy of "straight" aversive conditioning against the same aversive procedures following deep muscle relaxation training. Blake argued that because alcoholic behavior is often motivated and accompanied by high drive (anxiety or fear), the effects of aversive conditioning would be enhanced if the $\underline{S}$ could approach the treatment situation in a state of low drive. Also, motivational efforts would be more effective while the patient was deeply relaxed.

In a recent paper, Blake (1967) has published 12month follow-up data for both groups. The results show that 59 per cent of the relaxation-aversive group $(N=37)$ and 50 per cent of the straight aversive group $(N=25)$ were classified as either "abstinent" or "improved." The difference is not statistically significant though. Of major interest for the 
present study, however, was the aversive procedure used by Blake which incorporated escape from shock. Ss were given the necessary ingredients to mix a drink according to taste, and then were shocked on a 50 per cent reinforcement schedule as they sipped (without swallowing) the liquid, presumably on command. Shock could be terminated by spitting out the alcohol. On non-reinforced trials, the alcohol was ejected in response to a light signal. The number of conditioning sessions was not controlled, and they varied over a four-to eight-day pexiod.

In reviewing the various forms of punishment training in the aversive conditioning literature, Feldman and MacCulloch (1965) concluded that anticipatory avoidance learning -- a situation wherein the $\underline{S}$ can prevent the occurrence of the noxious stimulus (the UCS) by performing an instrumental response to the CS -- was particularly resistant to extinction. Support for this position, as mentioned previously, has been amply demonstrated by Solomon and Wynne (1953), Turner and Solomon (1962), and Solomon (1964).

In their work with homosexuals, Feldman and MacCulloch constructed two hierarchies, one comprising slides of nude and clothed males in ascending order of attractiveness, and the other of females in the reverse order of attractiveness. Briefly, a male slide (starting with the least attractive) was presented on a screen, and if the $\underline{s}$ did not switch off the slide within eight seconds, he received a shock. The 
shock stimulus was terminated when the illuminated slide was finally switched off. Introduction of the appropriate female slide (initially, the most attractive) was made contiguous with the removal of the male slide on many trials. The therapist controlled the removal of the female slide, but the $\underline{S}$ could ask for its return. This request, random ly met by the therapist, was increasingly made, as the presence of the fremale slide acted to delay the reappearance of a male slide. About 30 trials per session were given, but the number of sessions varied from five to 28. "Booster" sessions were also administered during the follow-up period.

Of 19 homosexuals treated at the time of publication, three failed to complete the procedures, six showed little, if any, improvement, and ten have altered their sexual orientation to some clinically significant degree. Follow-ups ranged from one month to 14 months.

Most interestingly, MacCulloch et al. (1966), using the same methodology as that described above for Feldman and MacCulloch, treated four alcoholics, all of whom returned to their previous drinking behavior following treatment. In assessing these failures, the authors questioned whether their patients' drinking behavior was any longer amenable to psychological control, due to the possible development of a pathological biochemical necessity for alcohol. It should be noted, however, that motor, gustatory, and olfactory components of the drinking response -- e.g., sipping, tasting, and smelling the 
alcohol -- were not shocked as part of treatment, as occurred in Blake's (1965) procedures with alcoholics. Instead, MacCulloch et al. relied almost entirely on visual stimuli such as slides of alcohol, and alcohol in a bottle and a glass in the S's visual field. And, in like vein, it might be hypothesized that Feldman and MacCulloch's moderate success with homosexuals may have been occasioned by the very fact that the visualperceptual mode plays a more vital part in the arousal and precipitation of homosexual behavior than it does for alcoholic behavior.

In summary, then, the case reports and studies mentioned so far have all used electrical stimulation as the noxious stimulus, and all have attempted to suppress some undesirable or unacceptable behavior-complex judged to be the result of maladaptive learning. In addition, a relative few have attempted to reinforce alternative behavior deemed incompatible with, and preferable to, the punished behavior -- at least to some degree. Beyond this, little in the way of comparison can be said. Various rationales and justifications purportedly based on experimental evidence have been offered, as well as a variety of classical and instrumental punishment procedures -- some simple and some more complex. Treatment intensities, controls, and lengths have varied. The patients and their behavioral syndromes, as well as treatment results, and follow-up procedures and lengths are not comparable. Often, follow-up data have not been offered at all. Rachman's (1965) Table 1 shows, for example, that of 114 persons reported in the literature who 
were treated with aversive conditioning procedures using electric shock for a variety of behavior disorders, 40 per cent were not followed past treatment termination.

Most importantly, however, the clinical literature offers little, if any, evidence bearing on the issue of whether the reinforcement of an appropriate escape response through long-duration electric shock cessation is more effective in establishing lasting behavior suppression than short-duration shock which is simply contiguous with a CS or target response. And, in no study to date has the noxious stimulus been administered in completely random fashion, either for control or treatment purposes.

With the above in mind, and before proceecing with a more formal statement of the hypotheses under investigation, attention will first be turned to the specific behavior syndrome dealt with in this study.

\section{The Problem Behavior: Smoking}

The target behavior selected for deconditioning was cigaret smoking. This habit appeared to be a satisfactory compromise between using a behavior syndrome of full clinical proportions such as alcoholism, with all the attendant problems for $\underline{S}$ selection, experimental control, and treatment which would have been entailed, and a non-clinical contrived response such as lever pressing which could have been conditionea before punishment training began. With a target response such as lever pressing, generalizability of results to clinical situations and problems would have been limited. 
Koenig and Masters (1965) list three criteria which should be satisfied in selecting a behavior for clinical experimentation:

1. The behavior should have the characteristic of maladaptiveness to keep within the paradigm of neurotic behavior.

2. The behavior must be potentially observable and occur in discriminable units.

3. The behavior should ideally occur with a fairly high frequency in the population at large.

Cigaret smoking appears to satisfy all three. It is an entrenched habit that has proved to be extremely difficult to modify for many smokers. The smoker is constantly being urged to maintain his habit by virtue of the massive and ubiquitous advertisement campaigns the cigaret manufacturers conduct. Smoking is socially acceptable, and the healthhazard issue raised by numerous investigations -- in particular, the Surgeon General's report (Smoking and Health, 1964) -linking cigaret smoking with lung cancer and a variety of other disease states, has apparently proven to be an insufficient deterrent. Hammond and Percy (1958) found that of 333 exsmokers identified in a random telephone directory sample of 3,560 smokers and ex-smokers, only 8.7 per cent had quit because of health concerns. However, 62.5 per cent of the exsmokers had given up the habit because of some condition, such as coughing or throat irritation, made worse by smoking. Apparently, the threat of lung cancer or some other disease, while seemingly a most powerful deterrent, is too far removed 
in time as a consequence of smoking to be a very effective negative reinforcer.

A great deal of effort has been expended investigating the psychological characteristics of smokers and non-smokers. As an illustration of this research activity, Fine et al. (1966) recently compiled a bibliography on the psychological aspects of smoking consisting of 143 studies conducted from January 1940 through September 1965. Matterazzo and Saslow (1960), in their extensive review of the literature, found that while smokers -- particularly heavy smokers -- and non-smokers differed on some 30 variables, none of the studies offered a single variable found exclusively in one group but absent in the other. The authors concluded that smokers seem to be slightly more neurotic, on the average, than non-smokers. At the individual level, however, this statistical relationship is meaningless. Also, they concluded, a clear-cut smoker's personality has yet to be found.

Much research has been aimed at modifying this physiological habit by substituting lobeline, a drug which produces the effects of nicotine, for nicotine (British Tuberculosis Association, 1963; Goodman and Gilman, 1960). The inconclusive results of lobeline studies indicate the probability that there is a more compelling component in smoking than mere physiological addiction, if in fact there is any such addiction involved.

Cigaret smoking has also been the subject of a number of behavior therapy studies. Several have focused attention 
on a comparison of the relative effectiveness of divergent treatment forms, and at least two of these have included an aversive conditioning procedure as one of the treatment methods. Koenig and Masters (1965), using seven therapists and 42 Ss between the ages of 19 and 23, compared the effectiveness of systematic desensitization, supportive counseling, and aversive conditioning methods. The aversive conditioning procedure consisted of short-duration shock administered to the $\underline{S}$ 's fingers as he proceeded to smoke two cigarets during the treatment session. All Ss received nine treatment sessions over a five-week span. While no significant treatment or interactional differences were found at the end of this period, significant therapist differences $(p<.05)$ were delineated. The groups showed a significant decrease in smoking consumption from pre-treatment levels (52 per cent reduction; $\mathrm{p}<.001$ ); six months later, the mean per cent reduction score had dropped to 19 per cent.

Ober (1967) compared the results of a "self-control" group, an aversive conditioning group, one which received treatment based on transactional analysis concepts and methods, and a no-treatment control group. The $\underline{S} s$ in the aversive conditioning group were instructed to self-administer shocks with a portable battery-operated shocker whenever they experienced the desire for a cigaret. Sixty $\underline{S}$ (college students) and two therapists were used. The $\underline{S}$ were seen for ten 50-minute group sessions over a four-week period. At termination of treatment 
and after a one-month follow-up, all treatment conditions were significantly lower than the no-treatment control group ( $\mathrm{p}<.001)$. Presumably, the cigaret consumption reduction rates for the experimental groups were also significantly lower than their pretreatment rates after treatment, although this is not explicitly stated. Following treatment, the per cent reduction rates were 81,100 , and 52 per cent for the self-control, aversive, and transactional groups, respectively. One month later, these rates were 49,58 , and 57 per cent, respectively. The no.-treatment control group showed a 3 per cent reduction in smoking following treatment. No significant treatment, therapist, or interactional differences were found, however.

Pyke et al. (1966) compared the results of one group receiving desensitization training, combined with regular group discussions on the ills of smoking, the viewing of films, and the reading of anti-smoking literature, with two control groups whose members merely kept frequency counts of their smoking consumption. The first control group Ss monitored their smoking for eight successive weeks, and the second kept frequency counts only during the first and eighth weeks. The experimental group Ss attended one group meeting and one private session each week for ten successive weeks. Fifty-five paid

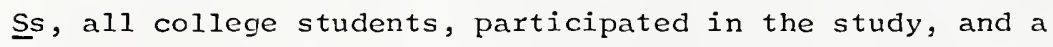
stated "desire to stop smoking" was the only selection criterion used. Apparently many, if not most, of the $\underline{S}$ s smoked Iess than 20 cigarets per day prior to their participation. The results after eight weeks clearly favored the experimental group over 
the two control groups $(p<.01)$, although little else can be definitely said with respect to the treatment procedures because of the potpourri of methods used. The follow-up data offered for the experimental group, while indicating some lasting effects of treatment over several weeks, were of questionable value as one third of the $\underline{S}$ in this group were not included. No follow-up data for the control groups were presented.

Other aversive stimuli have been used in an effort to decondition cigaret smoking. Wilde (1964) and Franks et al. (1966) used a mixture of smoke and hot aix as the noxious UCS, and cessation of this gaseous mixture was made contingent on the escape response of snuffing out the cigaret. In the first case, Wilde treated seven $\underline{S}$, between the ages of 25 and 54, all of whom smoked at least 20 cigarets daily. Three stopped smoking completely after two treatment sessions in two days. One was down to two cigarets per day after a single session, and another $\underline{S}$ changed over to a pipe after 20 sessions. Two others discontinued treatment and no mention was made of their progress, if any, or the number of treatment sessions received. No follow-up information was offered for any of the Ss. Franks et al. began treatment with 23 adult Ss but only nine completed the prescribed course -- 12 conditioning sessions within a four-week period. Of these nine, follow-up one-half year later revealed that four were not smoking, one was smoking "less", two were smoking as much as 
ever, and one had switched to a pipe. The ninth $\underline{s}$ was not heard from. The authors did not include the smoking rates for any of the Ss immediately following treatment termination. And, finally, Greene (1964) attempted to reduce the smoking rate of mental retardates in a free-operant situation with the use of white noise, superimposed upon continuous music, as the negative reinforcement. A control group without the superimposed white noise was also run. Twenty-one Ss, ranging in age from 16.5 to 25.6 and with a mean I.Q. of 67.5 , were used, and each participated in five consecutive daily sessions. The results showed that increased smoking rates were obtained over pre-treatment levels for both the experimental and control groups $(p=.10, p<.05$, respectively), and these findings were attributed to the positive reinforcing properties of barely audible clicking noises made by the relays. A second control group was then run without the clicking noises, and no change in smoking rates was found.

While the treatment procedures and methods of these studies concerned with the suppression of cigaret smoking are interesting and even innovative, they, like the studies reviewed earlier, offer little additional evidence bearing on the issues of this study. With this in mind then, a statement of the hypotheses investigated in this study is now in order.

\section{The Hypotheses Under Investigation}

Most of the clinical studies and case reports reviewed in this chapter have employed aversive conditioning treatment procedures based on a simple punishment model. That is, in 
attempting to obtain the suppression of unwanted behavior, a short-duration aversive stimulus has either been paired with the appropriate CSs, and/or both the target responses themselves. The prediction was made however (see pages 4-7), that increased and longer lasting behavior suppression would occur if patients were, in addition, positively reinforced for the performance of more desirable alternative instrumental acts incompatible with the behavior being punished.

One way to accomplish this end in the clinical situation would be to utilize an aversive conditioning procedure based upon the experimentally familiar "escape" paradigm. Here, the conditions governing the onset of the aversive stimulus would be identical with those for a "simple punishment" procedure; stimulus termination, however, would be made contingent upon the performance of the appropriate escape response, thereby serving to positively reinforce such instrumental acts.

A small number of the studies and clinical case reports reviewed earlier ( $\mathrm{Bl}$ ake, 1965; Feldman and MacCulloch, 1965; MacCulloch et al., 1966) have attempted to utilize, with varying degrees of success, treatment procedures based upon such an escape paradigm. A perusal of the clinical aversive conditioning literature indicates, however, that a controlled comparison of treatment procedures based upon the two punishment models has yet to be attempted. The first two hypotheses of this study, then, are concerned with this issue; whether, in fact, a clinical aversive conditioning procedure based upon an 
escape model will result in significantly greater or more effective response suppression than one based upon the "simple" punishment model.

Hypothesis 1 ( $\mathrm{Hl})--\underline{S} \dot{s}$ presented with an ordered set of stimulus items associated with, and related to cigaret smoking, and subjected to short-duration electric shock contiguous with the $\operatorname{cs}(s)$ or contingent upon the performance of the target response(s), will evidence a statistically significant reduction from pre-treatment levels in their mean cigaret consumption rate on the last experimental treatment sessionday, as well as during the 12-week follow-up period.

Hypothesis $2(\mathrm{H} 2)$-- (1) Ss presented with the same ordered set of stimulus items and shock onset conditions as the $\mathrm{HI}$ Ss above, but in addition subjected to electric shock which terminates only upon the performance of an appropriate escape response pre-determined by $\underline{E}$, will also evidence a statistically significant reduction from pre-treatment levels in their mean cigaret consumption rate on the last experimental treatment session-day, as well as during the 12-week follow-up period. (2) In addition it is predicted that this mean reduction in cigaret smoking will be significantly greater than that for the $H I$ Ss for the following: (a) during the course of the experimental treatment period; (b) specifically on the last experimental treatment session-day; and (c) during the 12-week follow-up period.

While the above hypotheses would appear to cover the central issue underlying the conception of this study, one 
further related consideration remains. As mentioned earlier, the experimental learning and conditioning literature has strongly indicated that, all other factors held constant, reinforcement delivered in a purely random or "chance" fashion has little lasting suppressive or facilitative effect on subsequent performance. All the clinical attempts utilizing aversive conditioning methods have at least assumed this much in the design of the treatment procedures. Nevertheless, as this experimentally derived finding has not been tested under clinical treatment conditions using an aversive stimulus, such as electric shock, it would seem appropriate, and even germane, to do so here. The results of SS run under random shock conditions would offer a "base for comparison," putting the data obtained under the two experimental treatment procedures described above into a more meaningful perspective. Therefore, the following hypothesis has been incorporated into this study. Hypothesis 3 (H3) -- Ss presented with the same ordered set of stimulus items as those under $H I$ and $H 2$, but subjected to randomiy administered electric shock of short duration, will not evidence a statistically significant reduction from pre-treatment levels, either on the last experimental treatment session-day, or during the follow-up period.

Hypotheses $\mathrm{H} 1, \mathrm{H} 2$, and H3, then, constitute the major hypotheses of this study. Addendum

After the data collection phase of the study had 
gotten under way, certain observations concerning the reactions of the Ss to the daily shock session regine became apparent. Several Ss, after completing approximately half of the experimental treatment sessions, attempted to "buy" their way out of, or otherwise attenuate their commitment to complete the sessions yet remaining. These $\underline{S} s$, in essence, offered to more quickly terminate or reduce their cigaret consumption if $\underline{E}$ in turn would agree to eliminate some or all of the experimental treatment sessions remaining to be run. This mattex will be expanded upon in the Discussion chapter. Accordingly, a fourth experimental group was then run to test the hunches generated by these observations, and the following hypothesis was included in the study.

Hypothesis 4 (H4) -- (1) Ss presented with the same experimental conditions as those under $\mathrm{H} 2$, but with the added provision that they can avoid completely the aversive conditioning treatment session on any day within the treatment period immediately following a day free of cigaret smoking, will also evidence a statistically significant reduction from pre-treatment levels in their mean cigaret consumption rate on the last ex-. perimental treatment session-day, as well as during the 12-week follow-up period. (2) In addition it is predicted that this nean reduction in cigaret smoking will be significantly greater than that for each of the other three groups for the following: (a) during the course of the experimental treatment period; (b) specifically on the last experimental treatment sessionday; and (c) during the 12-week follow-up period.

All references to significance in the above four hypotheses refer to the .05 level of significance. 


\section{CHAPTER II}

\section{METHOD}

\section{Subjects}

Twenty men and 12 women, all volunteers who wished to stop smoking, served as $\underline{S}$ for this study. Most of these participants were either "middle level" professional staff members or nonprofessional personnel of the Edward Hines Jr. V. A. Hospital, Hines, Illinois. Examples of the former were occupational therapists, corrective therapists, and medical technologists; and of the latter, secretaries and ward assistants. In addition, a small number of $\underline{S}$ (five) were recruited through a small classified advertisement placed in the local neighborhood newspapers calling for volunteers for a V.A. hospital-sponsored study, who wished to give up cigaret smoking. Hospital personnel were obtained through the use of bulletin board notices, personal contact, or referrals by other staff members familiar with the investigation.

Prospective $\underline{\text { Ss }}$ were assessed for suitability in a preliminary interview and then randomly assigned, as they became available, to one of the treatment groups. These groups were labeled the $\mathrm{Hl}, \mathrm{H} 2$, and $\mathrm{H} 3$ groups, corresponding to the three major hypotheses, respectively. Group 4 was labeled and filled in like manner when it became operational midway in the data collection phase. Each group consisted of eight $\underline{\text { Ss; groups }}$ 
$\mathrm{HI}, \mathrm{H} 3$, and $\mathrm{H} 4$ received three female $\underline{\mathrm{S}}$ each, while group $\mathrm{H} 2$ received two.

Those interested in participating were selected as Ss if they were between the age's of 25 and 49 , smoked an average of at least one but not more than two and a half packs of cigarets daily, and had been continuous smokers for at least the past four years prior to their participation in the study. In addition, all Ss had to voluntarily desire to stop smoking and be willing to cooperate with all the study's requirements. Those who indicated that they had been able to stop smoking on their own for periods longer than two weeks in the past were eliminated from further consideration.

Analysis of variance on data of age, number of cigarets smoked per day, and total number of years smoked prior to participation in the study revealed no significant differences between the four groups at the .OI level of significance (Tables 9,10 , and 11 ; Appendix A).

\section{Apparatus}

\section{Electric Shock Source}

A matched impedance shock generator was specially constructed for use in this study. The circuit consisted of a variable transformer with $115 \mathrm{v} A C$ input and $0-120 \mathrm{v}$ output which was connected to a $1,000 \mathrm{~V}$ CT step-up transformer. The output of the latter was then connected through a $100 \mathrm{k}, 100$ w power resistor, a $0-10 \mathrm{milliammeter,} \mathrm{and} \mathrm{two} 1 / 100 \mathrm{amp}$. fuses to $\underline{S}$. The intensity of the shock output to $\underline{S}$ was varied by setting the dial on the variable transformer, and the 
milliammetex allowed monitoring of the actual shock intensity delivered. While the resistance of $\underline{S}$, and therefore the inpedance of $\underline{S}$, could be matched directly by varying the value of the power resistor, this was not done, as it was not deemed necessary.

This circuit made use of such safety features as an isolation transformer which physically separated $\underline{S}$ from the wall current, thereby preventing the occurrence of dangerously intense shocks and burns, and a circuit fused on both sides of S. This latter restricted the variability of shock and eliminated large surges of current from the circuit. In addition, the chassi.s was grounded.

The $\underline{S}$ was connected to the shock circuit via Nu-way snap leads, which were in turn fastened to snaps embedded in rubber finger protectors. These latter were trimmed to provice a band approximately 3/4" wide, which slipped over the finger like a ring. Both electrodes were placed on the fingers of one hand, the index and third; thus, no current passed across $\underline{S}^{\prime}$ s body. A light coating of Sanborn Redux electrode jelly was first applied to the fingers.

Additional features of the unit consisted of a toggle on-off circuit switch and indicator light, an electric counter, and a remote switch for administering the shocks.

Timer

The device employed was an interval timer with automatic reset made by Industrial Timer Corporation (Model P-A.R). Two plug receptacles, one for a remote switch and the second 
for a standard AC load, were provided. Load-switch contacts were rated at 15 amps., the time cycle was $0-15$ seconds, and the dial divisions were in quarters of a second. Random Interval Programmer

The device used was a Gerbrands programmer, incorporating a Telechron synchronous motor (type B3, 110/120 v, $60 C Y$ ) set at one RPM, and a standard microswitch. A loop of $16 \mathrm{~mm}$ leader film, taking 30 minutes for one complete revolution and randomly punched 40 times, was used to trip the microswitch. The punch-hole diameter allowed the shock circuit to remain open for one second with each successive activation.

\section{Experimental Room}

All preliminary interviews and experimental conditioning sessions were conducted in an easily accessible private office reserved for this purpose. The apparatus was arranged so that $\underline{S}$, sitting on the opposite side of a desk from $\underline{E}$, was unable to see the manipulation of the stimulus cards, remote control switch, or shock generator dial settings. While the shock generator sat on a low, small table at the right of $\underline{E}$, no attempt was made to conceal its presence. The random interval programmer was mounted on a board attached to the far edge of the table in such a way that neither $\underline{S}$ nor $\underline{E}$ could determine beforehand when the next shock would occur.

In addition to the above-mentioned apparatus, such items as chewing gum, Iife savers, peanuts, dietetic candies, ash trays, and matches were provided in the experimental room. 


\section{Procedures}

In order to maximize conditioning and enhance the resistance to extinction equally across all groups, certain variables mentioned in the literature as being relevant to punishment training were incorporated into all the treatment procedures. Thus: initial shock intensities for every session were introduced at levels perceived by the individual $\underline{S}$ s as being dis.. tinctly unpleasant (Miller, 1960): novel stimulus items were introduced from time to time in accordance with a pre-determined schedule (McNamara and Wike, 1958) and, shock intensities were varied randomly during each session from levels perceived as just unpleasant to levels which bordered on being painful (Church, 1963; Solomon, 1964).

Preliminary Interview

Prospective Ss for all groups were individually seen by E in a preliminary interview. If all selection criteria were met, a brief smoking history was then obtained, and the requirements for further participation were explained. These latter included agreeing to: (1) come in for daily sessions over the three-week experimental period for a total of 15 sessions, (2) keep a daily count of cigarets consumed through completion of the experimental sessions; and (3) be available for follow-up purposes over a three-month period. Ss were then asked to continue their usual smoking practices until their first experimental session, and also to begin keeping daily cigaret consumption frequency scores. Small cards the size of a cigaret package were provided by E for this purpose. Ss were cautioned not to rely on memory for 
the daily totals but to mark the cards each time a cigaret was lit, regardless of the number of puffs taken. Ss were asked to bring in these daily tallies along with two or three packages of their favorite brand of cigarets for deposit, when they returned for the first experimental session. Tinis latter request was made so that the act of purchasing cigarets would not be tacitly encouraged once the sessions began. The mean of the daily cigaret consumption frequency scores for the period between the preliminary interview and the first experimental session provided each $\underline{s}^{i} s$ cigaret consumption base rate. This period varied from five days to a week and always included three weekdays and a weekend.

Also at this time a brief explanation of smoking behavior in simple learning theory terms was offered by E. Smoking was conceptualized as learned behavior which had become a highly practiced habit in a variety of life situations. Ss were told that the purpose of the experimental treatment sessions was to provide an opportunity for "unleaming" this behavior through the application of learning principles; specifically, by associating an unpleasant stimulus - - shock -- with that behavior which had come to acquire rewarding properties. The experimental nature of the study was mentioned, and $\underline{E}$ offered himself as an "advanced graduate student in clinical psychology" who was conducting research on methods which would help people give up the cigaret smoking habit. Before concluding the preliminary interview, several demon-

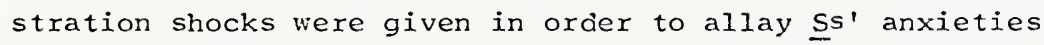


about getting shocked, and to establish initial thresholds for uncomfortableness and pain. An appointment for the first experimental session was then arranged.

Approximately 35 individuals were disqualified from further participation during this interview for one of several reasons. A few sinoked less than one pack of cigarets daily or had not been smoking long enough. About 20 others were unable to attend sessions on a daily basis. The remainder either did not wish to subject themselves to electric shock, or had second thoughts about giving up cigarets.

\section{Stimulus Items}

The stimulus items consisted of components of the smoking behavioral chain, ideational stimuli, and various "precipitating stimuli" such as, e.g., the smell of cigaret smoke, the sight of someone lighting up, and seeing a magazine advertisement for cigarets. Table 1 lists the stimulus items used, but not necessarily in the order presented. As indicated, many of the items were presented during every session, while others were introduced at pre-determined points after the sessions began. Also, while all $\underline{\text { ss }}$ received the same number of items for each session, the content of several -primarily the ideational items -- sometimes varied in accordance with the idiosyncrasies of the individual s's smoking behavior pattern. Thus, when asked to imagine, e.g., the occasion for taking the first cigaret of the day, one $\underline{s}$ might "see" himself reaching for his pack immediately upon awakening, while anather might visualize taking his first cigaret of the day after breakfast. 


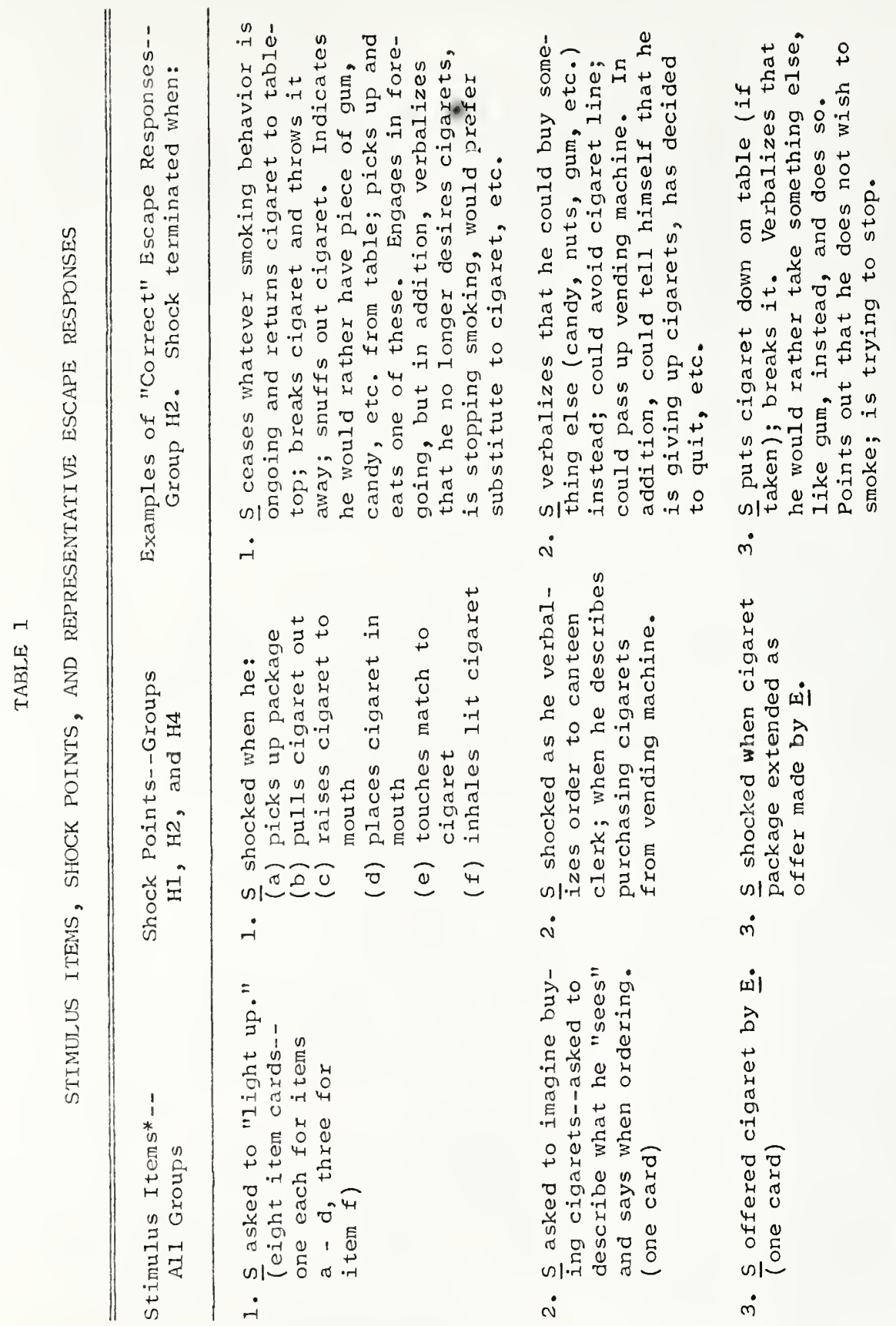




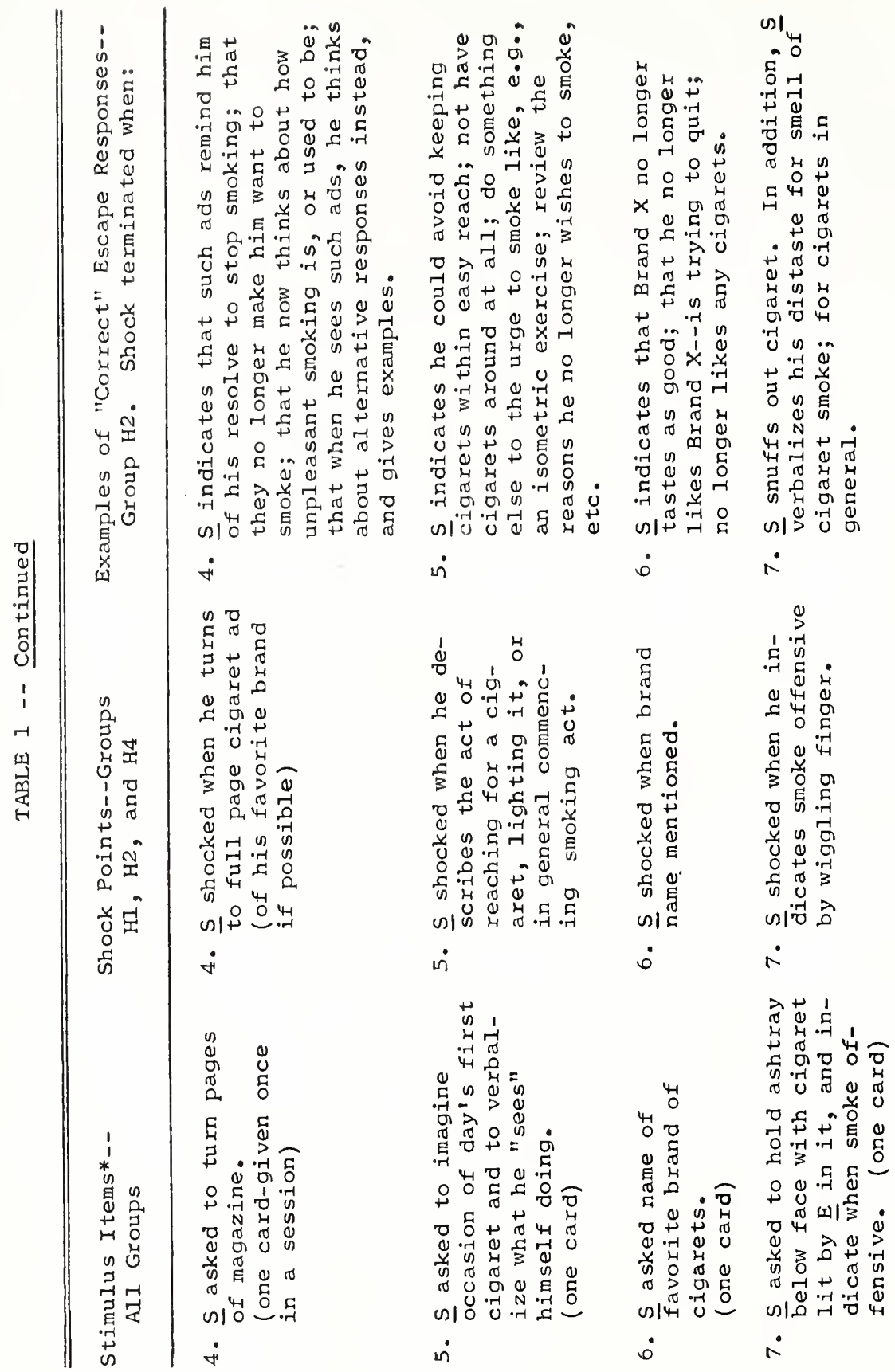




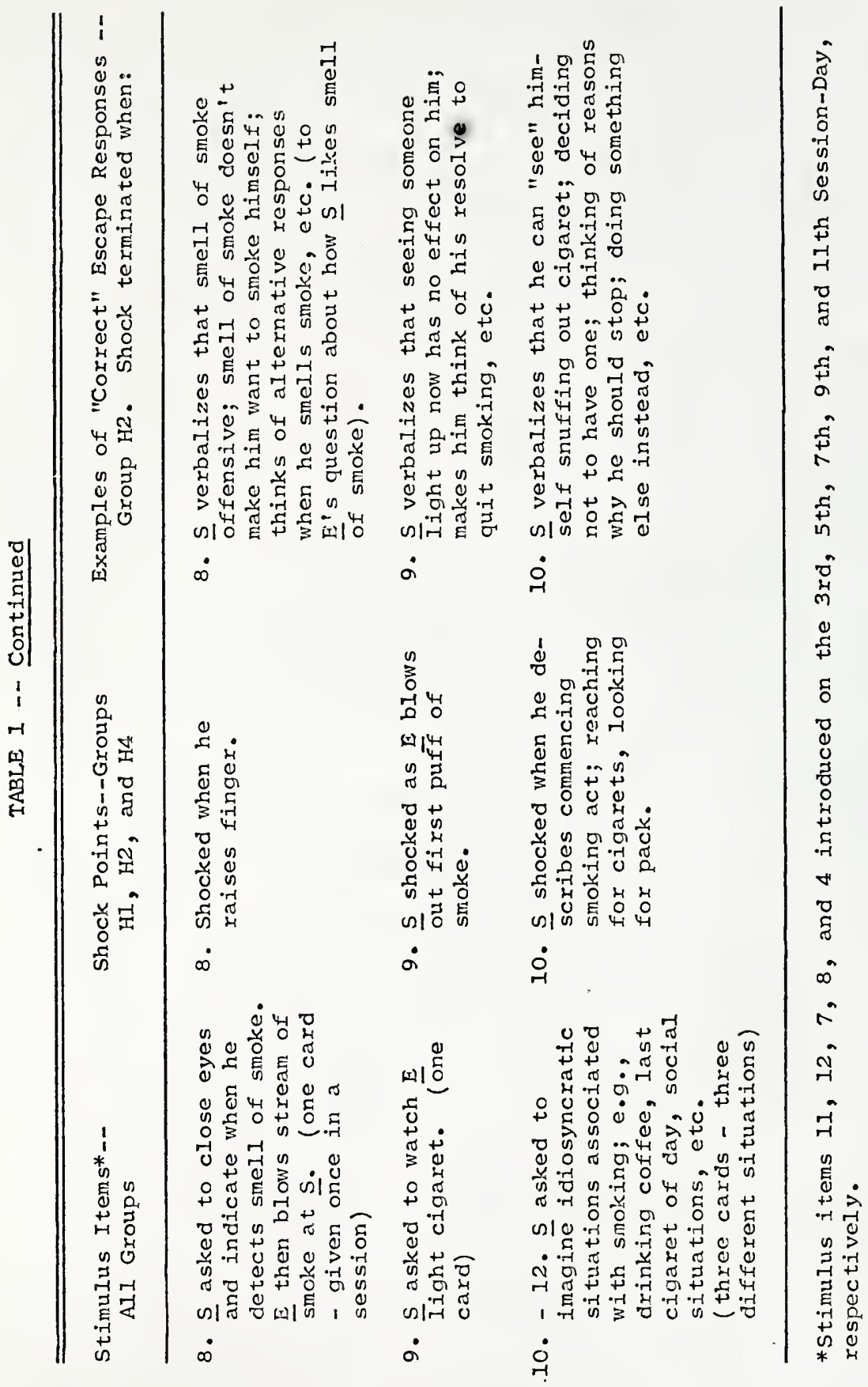


Item presentation was random. Each was written on an index card, and the cards were shuffled before each session. On occasion, changes were made by $\underline{E}$ as the individual cards came up to provide for a more logical ordering of the items. Experimental Shock Sessions

The format followed during the sessions was essentially the same for all groups. Upon entering the experimental room, Ss pulled the two electrode-embedded rubber bands on the index and third fingers of their smoking hand so that the metal snaps were positioned against the palm side of the fingers. The bands were placed far enough back on the fingers so that normal finger dexterity was not unduly hampered. The previous day's cigaret consumption tally was then recorded by $\underline{E}$. Stimulus item presentation began after a quick check by $\underline{E}$ determined that the electrodes were positioned correctly and the apparatus'was connected properly. For all groups, the sessions terminated when the electric counter on the shock generator indicated that the $\underline{S}$ had received 40 shocks. The sessions lasted, on the average, about 30 minutes, and, with the exception of the $H 4$ group $\underline{S} s$, all $\underline{\text { Ss }}$ received a total of 600 shocks over the 15 sessions. The H4 group $\underline{S}$ s averaged 350 shocks over this period.

At the start of the first session, each $\underline{S}$ was advised that no specific restrictions would be placed on his smoking behavior during the duration of the study. It was suggested at that time, however, that if he attempted to "do something else instead" in response to the urge to smoke, progress 
towards the goal of terminating smoking would possibly be aiced. Several alternative responses were then suggested as possibilities. Examples of these were the following: taking a deep breath and holding it for 20 or 30 seconds, chewing or eating some gum or candy, taking a few sips of cold water, performing an isometric exercise, or reviewing one's own reasons for wanting to stop smoking. It was then suggested that each $\underline{S}$ experiment with such alternatives until he found those which best suited him.

This approach was decided upon for several reasons. It soon became apparent in working with several pilot $\underline{S}$, and in general conversations with smokers, that many, if not most smokers had at one time read ox heard about various ploys one could utilize to siop smoking. Many had tried one or more of these methods themselves. And too, some Ss wondexed whether they should "fight" the effects of the experimental procedures, or do anything to help on theix own. Telling ss they could try to reduce their cigaret consumption away from the sessions, as well as suggesting some things that they could do, helped to standaxdize $\underline{S}$ attitudes and motivation, and also introduced a neasure of expeximental control.

HI Group -- Ss in this group received electric shocks of one second duration, administered at the points indicated in column 2 of Table 1. Shock onset was controlled by means of a remote control hand sivitch held below desk level; the shock stimulus was terminated by the circuit's autonatic reset timer. No special instructions were additionally given to the HI group $\underline{S}$. 
H2 Group -- While the Ss in this group received shocks of variable duration, the shock onset points were identical to those for $\underline{S}$ s in the $H 1$ group above. Before each H2 group $\underline{S}$ entered the experimental room, the automatic reset timer was disengaged from the circuit, thus enabling E to control both

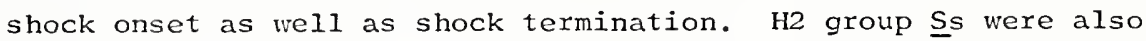
given the following special instructions at the beginning of the first experimental session in addition to the general instructions noted previously:

Once the shock begins, it will not turn off until you proceed to do something or say something, either as an alternative to what you will be doing upon my request, or in response to a question $I$ might ask you. Your task, then, will be to respond in such a way that the shock will be turned off. Remember, you yourself will be able to turn off the shock every time by responding correctly in each situation. Let's take an example.

The $\underline{\mathrm{S}}$ was then asked to "light up", and shock onset occurred as he put the cigaret in his mouth, but before he lit it. "Correct" responses here included removing the cigaret and laying it down on the table, breaking the cigaret, putting it back in the pack, or throwing it in the waste basket. If the $\mathrm{S}$ did not immediately dispose of the cigaret, or if he removed it from his mouth but continued to hold it in his hand, $\underline{E}$ then said, "Remember now, you can terminate this shock. What can you do with that cigaret in order to turn the shock off?" In all instances, this was sufficient to prompt the $\underline{S}$ to get rid of the cigaret. Item presentation then proceeded in regular fashion.

There were several "correct" responses, then, which the $\underline{\mathrm{S}}$ could offer for most of the items. The third column of 
Table 2 lists examples of escape responses which were defined as acceptable. To deter stereotypic or repetitious responding to any given item as it came up through the 15-session sequence, and to encourage the development of an array of incompatible-tosmoking response tendencies, the same escape response was not always allowed to be the correct one. Often, when a $\underline{S}$ would respond in a manner which had previously proved to be "correct," the shock would, nevertheless, continue, and $\underline{E}$ would say, e.g., "Yes, but what else could you do in this case?" H3 Group -- The Ss of this group received electric shocks of one second duration, administered at random intervals. The shock generator was plugged into the random programmer before the $\underline{S}$ entered the experimental room, and immediately after the electrodes were positioned, the circuit was activated. Thus, E neither controlled shock onset nor shock termination. No special instructions were additionally given to the $\underline{S}$ in this group. It was often necessary, however, for $\underline{E}$ to terminate the $\underline{S}^{\prime} s$ performance at the point at which $\underline{S}$ in the other three groups were getting shocked, in order to maintain stimulus item equivalency for this group. For example, if the stimulus item card called for shock onset to occur as the $\underline{S}$ placed the cigaret in his mouth, the $H 3$ group $\underline{S}$ was told at this point to dispose of the cigaret and place the cigaret package back on the table. H4 Group -- The procedures for $\underline{S}$ in this group were identical to those already described for the H2 group Ss, with the following exception: At the end of the first experimental shock session, each $\underline{S}$ was told that any given subsequent session 
could be avoided if, on the immediately preceding day, he completely refrained from smoking any cigarets. (The two weekend days were counted as one day.) Each $\underline{S}$ did, however, have to "report in" by phone or in person each weekday morning in order to apprise $\underline{E}$ of his smoking performance during the preceding day. It was pointed out to each $\underline{S}$ that, in effect, he could determine the number of sessions he would have to attend during the three-week experimental period.

\section{Follow-Up}

Cigaret consumption follow-up data were collected for al1 Ss two, six, and 12 weeks after treatment termination. Ss were contacted two days prior to these dates and asked to keep tallies over a three-day period. Three-day means were then computed for the follow-up cigaret consumption scores. At the end of the 12-week follow-up period, each $\underline{S}$ was asked to informally express any impressions or thoughts he had about the study or his participation in it. These will be explored in the Discussion chapter. 


\section{CHAPTER III}

\section{RESULTS}

The dependent measure of this study consisted of the per cent reduction scores computed for each $S$ during both the experimental treatment and follow-up periods. These scores were based upon the mean of each S's pre-treatment cigaret consumption tallies, obtained between the preliminary interview and the first experimental session-day. Each individual's pretreatment mean was given a value of zero, and any subsequent reduction in smoking was converted from this base line measure into a per cent reduction score (or, in another sense, a per cent improvement score). For example, if a $\underline{s}^{\prime} s$ pre-treatment mean consumption rate had been 40 cigarets per day, and he then smoked 30 cigarels during the second session-day, his per cent reduction score for that day would have been 25 per cent ( 30 divided by $40=.75 ; .75$ subtracted from 1.00 multiplied by $100=25$ per cent). A per cent reduction score of 100 then, would indicate that the $\underline{S}$ did not smoke any cigarets on that particular day. Individual per cent reduction scores were computed from the number of cigarets each $\underline{S}$ smoked on each of the 15 session-days, and from the mean number of cigarets smoked during the three-day intervals two, six, and 12 weeks after treatment termination. These individual per cent reduction scores are shown in Appendix $B$. A total of 11 


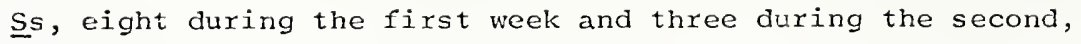
- were dropped from participation after treatment began. Five of these decided they no longer wanted to stop smoking, and the other six either couldn't make the treatment sessions on a daily basis or failed to show up for their scheduled appointments. The partial records of these 11 Ss were not included in the data analysis nor are they shown in Appendix B.

Figure 1 shows the MPSR scores of the four groups plotted across both the experimental treatment and follow-up periods. As hypothesized, the $\mathrm{H} 4$ group MPSR scores are consistently larger than those for the other three groups across the sessiondays, but the relative rankings of the other three group curves are less pronounced. The 15 th session-day MPSR scores of 97 , 91, 89, and 86 for the $\mathrm{H} 4, \mathrm{H} 2, \mathrm{H} 1$, and $\mathrm{H} 3$ groups, respectively, are ranked in accordance with the group ordering predicted by the hypotheses. Two, six, and 12 weeks after treatment termination, however, the relative group rankings can again be seen to be ordered somewhat differently, with the largest MPSR scores consistently being attained by the H2 group.

Perhaps the most notable feature of Figure 1, however, is not the relative orderings of the group MPSR scores at specific points on the horizontal axis, but rather the high degree of concordance of the curve slopes across both the session-days and the follow-up periods. This concordance suggests that the differential effects of the experimental procedures on the mean smoking reduction rates of the groups were not 


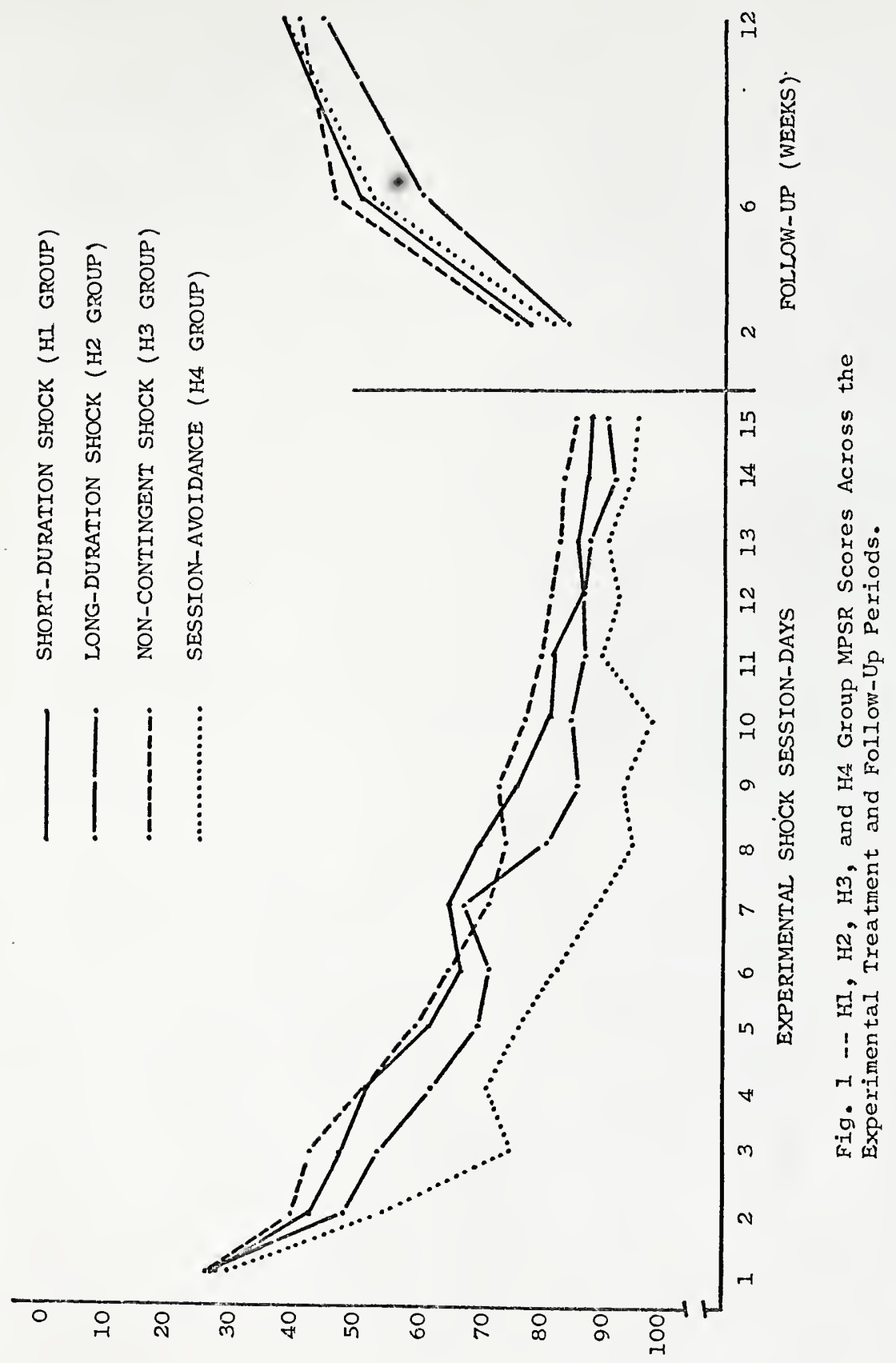


great throughout either the experimental treatment or followup phase of the study. Analysis of the data does, in fact, bear this out.

Table 2 shows the results of a repeated measurements analysis of variance of the $\mathrm{HI}, \mathrm{H} 2$, and $\mathrm{H} 3$ group MPSR scores compiled during the experimental treatment period. The $\mathrm{H} 4$ group was excluded from this primary analysis, as the $\underline{S}$ in this group differed from those in the other three in the number of shock sessions they received. (The mean number of shock sessions administered the $H 4$ Ss was 8.5 ; the least number of sessions a H4 group $\underline{\mathrm{S}}$ received was five, and the most, 12.)

TABLE 2

REPEATED MEASUREMENTS ANALYSIS OF VARIANCE OF THE MPSR SCORES ACROSS SESSION-DAYS--GROUPS H1, H2, AND H3

$$
\mathrm{N}=24
$$

Sources of Variation df Mean Squares $\quad F \quad P$

Between Ss

$\begin{array}{lccc}\text { Group Procedures } & 2 & 901.50 & <1.00 \\ \text { Şs Within Groups } & 21 & 5031.05\end{array}$

Within Ss

\begin{tabular}{lcccc} 
Session-Days & 14 & 7901.36 & $50.40<.005$ \\
$\begin{array}{c}\text { Procedures by } \\
\text { Session-Days }\end{array}$ & 28 & 82.25 & $<1.00$ & - \\
$\begin{array}{c}\text { Session-Days by Ss } \\
\text { Within Groups }\end{array}$ & 294 & 156.76 & \\
\hline
\end{tabular}


From the results of this analysis of variance, it is evident that neither the differential effects of the various group procedures, nor the procedures by session-days interaction were significant sources of variance. The main sessiondays effect--i.e., the effect of treatment repetition over time-was, however, highly significant $(\mathrm{F}=50.40 ; \mathrm{P}<.005)$. Part (2) a of Hypothesis 2, then, was not supported.

The $\mathrm{H} 1, \mathrm{H} 2$, and $\mathrm{H} 3$ group MPSR scores across sessiondays were then combined, and a Neuman-Keuls test of all the ordered pairs of session-day means was computed. The results, shown in Table 3, corroborate what the group curves suggest in Figure 1; namely, that most of the smoking reduction occurred during the first half of the experimental treatment period. As Table 3 indicates, no further increase in per cent smoking reduction, from the eighth session-day to any of the remaining seven session-days, attained statistical significance at the .05 level of confidence.

In order to determine what effect the inclusion of the $\mathrm{H4}$ group MPSR scores would have on the Group Procedures F ratio, a second ancillary repeated measurements analysis of variance was computed. Despite the slight divergence of the H4 group curve seen in Figure 1 , the results of this second analysis, shown in Table 4, parallel those obtained in the first analysis. It is interesting to note that the Group Procedures mean square is, relatively speaking, much larger than the corresponding one 


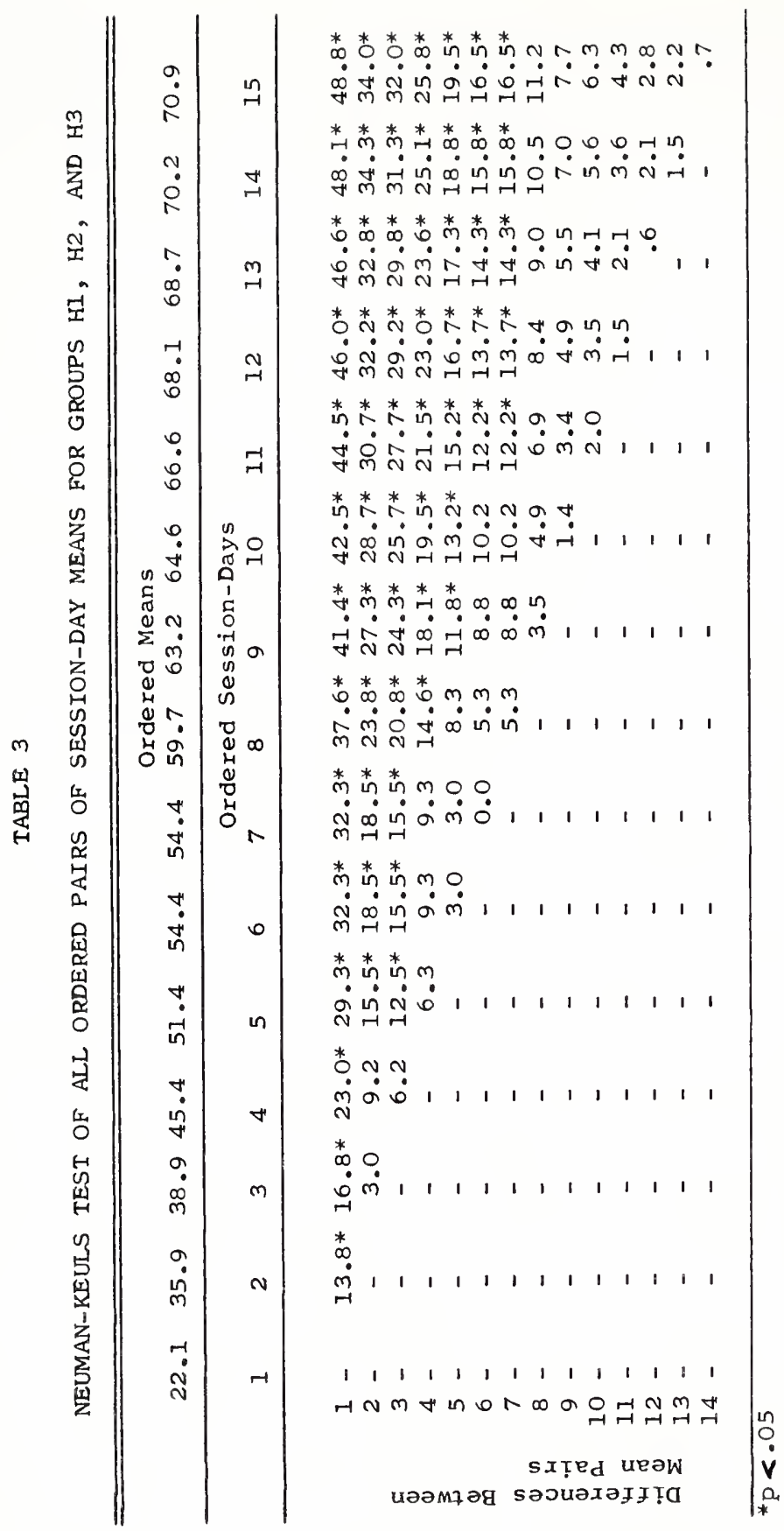


obtained in the first analysis. Nevertheless, only the SessionDays main effect was, again, a statistically significant source of variance $(F=56.85 ; \mathrm{P}<.005)$. These results, then, failed to confirm both Part (2)a of Hypothesis 2 as well as Part (a) of Hypothesis 4.

TABLE 4

REPEATED MEASUREMENTS ANALYSIS OF VARTANCE OF THE MPSR SCORES ACROSS SESSION-DAYS--GROUPS H1, H2, H3, AND H4 $N=32$

Source of Variation

df Mean Squares F P

Between Ss

Group Procedures 3 5723.33 1.38

Ss Within Groups 28 4159.00

Within Ss

Session-Days

Procedures by

Session-Days

Session-Days by Ss 392 Within Groups
14

42
$10312.71 \quad 56.85<.005$

$145.28<1.00$

181.39

Finally, with respect to the data obtained during the experimental treatment phase of the study, two analyses of variance of the 15th session-day MPSR scores were computed. While all $\mathrm{HI}, \mathrm{H} 2$, and $\mathrm{H} 3 \mathrm{~S} s$ received an experimental shock treatment on this last session-day, six of the eight H4 group Ss avoided a shock session on the last day because they had abstained from snoking on the preceding day. To control, 
then, for the effects of shock, per se, on cigaret consumption on this last experimental treatment day, only the MPSR scores of the first three groups were included in the first, or primary, analysis of variance. The results, summarized in Table 5, reveal no significant differences between the MPSR scores of the three groups; therefore, they failed to support Part (2)b of Hypothesis 2 .

\section{TABLE 5}

ANALYSIS OF VARIANCE OF THE MPSR SCORES ON THE 15 th SESSION-DAY--GROUPS H1, H2, AND H3

$$
\mathrm{N}=24
$$

\begin{tabular}{lcccc}
\hline Source of Variation & df & Mean Squares & F & $P$ \\
\hline $\begin{array}{l}\text { Procedures Between } \\
\text { Groups }\end{array}$ & 2 & 47.79 & $<1.00$ \\
$\begin{array}{l}\text { Procedures Within } \\
\text { Groups }\end{array}$ & 21 & 256.58 & \\
\hline
\end{tabular}

A second analysis of variance, this time including the H4 group MPSR scores on the 15th session-day, was additionally calculated. The results, shown in Table 6 , also indicate no significant differences between the group MPSR scores, although again, this second Group Procedures mean square is larger than that obtained in the first analysis. The results again did not support part (2)b of Hypothesis 2, as well as Part (b) of Hypothesis 4 . 
TABLE 6

ANALYSIS OF VARIANCE OF THE MPSR SCORES ON THE 15 th

SESSION-DAY--GROUPS $\mathrm{H} 1, \mathrm{H} 2, \mathrm{H} 3$, and $\mathrm{H} 4$

$\mathrm{N}=32$

\begin{tabular}{lcccc}
\hline \hline Source of Variation & df & Mean Squares & F & P \\
\hline $\begin{array}{l}\text { Procedures Between } \\
\text { Groups }\end{array}$ & 3 & 169.37 & $<1.00$ & - \\
$\begin{array}{c}\text { Procedures Within } \\
\text { Groups }\end{array}$ & 28 & 205.97 \\
\hline
\end{tabular}

With respect to the data compiled during the follow-up period, a final repeated measurements analysis of variance of the MPSR scores of all four groups computed two, six, and 12 weeks after treatment termination was then calculated. As the independent variable -- the passage of time -- operated equally for all groups, the H4 group MPSR scores were included, and only one analysis was made. The results are summarized in Table 7. Again, the differential effects of the experimental procedures, this time on the recovery rates of the groups, were not statistically significant at the .05 level of confidence, nor, was there a statistically significant Procedures by Follow-Up interaction effect. The main effect of time (Follow-Up) was, however, significant beyond the .005 level of confidence. These results, then, failed to support Part (2)c of Hypothesis 2 as well as Part (b) of Hypothesis 4. 
TABLE 7

REPEATED MEASUREMENTS ANALYSIS OF VARIANCE OF THE MPSR SCORES TWO, SIX, AND 12 WEEKS AFTER

TREATMENT TERMINATION--GROUPS $\mathrm{H} 1, \mathrm{H} 2, \mathrm{H} 3$, and $\mathrm{H} 4$ $N=32$

Source of Variation $\quad$ df $\quad$ Mean squares $\quad F \quad P$

Between Ss

Group Procedures

3

454.33

$<1.00 \quad-$

Ss Within Groups

28

2312.32

Within Ss

Follow-Up

2

12356.00

$37.43<.005$

Procedures by

6

68.00

$<1.00$

Follow-Up

Follow-Up by $\underline{\text { s }}$

Within Groups

56

330.09

Combining the MPSR scores of all the groups, a Neuman-

Keuls test of the differences between all ordered pairs of the two, six, and 12-week means was then computed (Table 8). The results indicate that the differences between both the two and six-week, and six and 12-week mean MPSR scores were significant at the .01 level of confidence. It is interesting to note that the first mean difference is approximately twice as large as the second, despite the fact that the six-to-12-week interval was 50 per cent longer than the two-to-six-week interval. Thus, it would appear that the smoking recovery rate, as suggested by the group curves during follow-up (Figure 1), is a negatively accelerating function of the passage of time. 
TABLE 8

NEUMAN-KEULS TEST OF ALL ORDERED PAIRS OF FOLLOW-UP MEANS FOR GROUPS $\mathrm{H} 1, \mathrm{H} 2, \mathrm{H} 3$, AND $\mathrm{H} 4$

\begin{tabular}{|c|c|c|c|c|}
\hline & & 40.0 & $\begin{array}{l}\text { Ordered Means } \\
52.8\end{array}$ & 78.6 \\
\hline & & $1(12$ & $\begin{array}{l}\text { Follow-Up Points } \\
2 \text { (6 wks.) }\end{array}$ & 3 (2 wks.) \\
\hline $\begin{array}{l}\text { Differences } \\
\text { Between }\end{array}$ & 1 & - & $12.9 *$ & $38.6 *$ \\
\hline Mean Pairs & 2 & - & - & $25.7 *$ \\
\hline
\end{tabular}

To determine whether the mean cigaret consumption scores of the four groups were significantly lower than their respective pre-treatment levels on the 15th session-day, and two, six, and 12 weeks after treatment termination, a single t-test (onetailed) of the difference between the over-all pre-treatment and 12-week correlated means was computed $(x=.24)$. The three-day interval means of each $\underline{S}$, compiled from the actual numbers of cigarets smoked by all 32 Ss on these two occasions, were the data used in the calculations. (See Appendix C). The "t" value obtained (5.29) was significant beyond the .0005 level of confidence. (Pre-treatment $\mathrm{M}=34.3$, S.D. $=$ $6.96 ; 12$-week $M=20.3$, S.D. $=13.24$. )

The justification for using the over-all pre-treatment and 12-week means to compute only one "t" followed from the fact that the pre-treatment cigaret consumption scores, and the 15th session-day, and follow-up MPSR scores of the four groups 
did not differ significantly from each other (see Table 10, Appendix A; Tables 6 and 7). Thus, if the "t" value for the difference between the over-all pre-treatment and 12 -week means was significantly large, then the differences between the overall pre-treatment mean and the over-all 15th session-day, twoweek, , and six-week cigaret consumption rate means would also have to be statistically significant; these latter over-all mean differences would have been even larger than the difference between the over-all pre-treatment and 12 -week means. And, since the cigaret consumption rates of the four groups themselves did not differ significantly from each other at any point, then it could be said that the cigaret consumption rate of each group on the last day of treatment, and during follow-up, was significantly lower than its pre-treatment level. Thus, Hypothesis 1, Part (1) of Hypothesis 2, and Part (1) of $\mathrm{Hy}-$ pothesis 4 were supported. Hypothesis 3 was not.

In summary, then, the prediction that the cigaret consumption rates of the four groups would differ significantly from each other in a prescribed fashion, as a function of the differential effects of the experimental procedures each group received, was not supported in any way. This was true for both the experimental treatment and follow-up phases of the study. Irrespective of the nature of the aversive shock treatment received, the mean performance of each group was essentially the same as that of the other three. The prediction that the cigaret consumption rates of the $\mathrm{Hl}, \mathrm{H} 2$, and $\mathrm{H} 4$ groups on the last day of treatment, and during follow-up 
would be significantly lower than their respective pre-treatment levels was supported; the prediction that the H3 group's cigaret consumption rates would not be significantly lower was not.

Additionally, it was observed that the Session-Days main effect (the effect of treatment repetition over time) was the only significant source of variance contributing to the reduced cigaret consumption rates of the groups during the experimental treatment phase. Upon combining the MPSR scores of the $\mathrm{H} 1, \mathrm{H} 2$, and $\mathrm{H} 3$ groups, it was found that after the eighth session-day, no further decrease in smoking during the remaining seven session-days attained statistical significance. Finally, during the follow-up phase, smoking recovery, as evidenced by the increased smoking consumption rates of all four groups, appeared to be a negatively accelerating function of the passage of time. There were no other significant sources of variance. 


\section{CHAPTER IV}

\section{DISCUSSION}

The two major outcomes of this research were the following: (1) the failure of the results to demonstrate a significant Group Procedures main effect, both during the experimental treatment and follow-up phases; and (2) the finding that cigaret consumption rates of the groups, all varying together, were significantly lower than their pre-treatment levels during both the experimental treatment and follow-up phases. Thus, the inherent differences imputed to the treatment procedures as a function of the conditioning models upon which they were based, were greatly attenuated in practice. Even so, the above findings demonstrate that treatment variables common to all four experimental treatment situations were operating to effect a significant smoking reduction for all four groups. This common over-all treatment effect was, in all probability, either the result of (1) confounding arising from the procedures themselves which served to make the procedural effects more sinilar than dissimilar, (2) the presence of uncontrolled situational variables, common to all the treatment conditions, which overshadowed or negated the differential effects of the individual treatment procedures, or (3) some combination of both (1) and (2). 


\section{Confounding as a Function of the Procedures}

\section{Reactive Inhibition}

During each experimental treatment session of approximately 30 minutes' duration, 40 stimulus item presentations were made. The $\mathrm{HI}$ and $\mathrm{H} 3$ group $\underline{S}$ simply responded to each and were, at least in the case of the former $\underline{S}$, then shocked for one second at the appropriate shock point. The situation was, however, more complicated for the H2 and H4 group Ss. Upon the presentation of each stimulus item, these $\underline{S}$ sad to first begin the task of arriving at the "correct" escape response which would terminate the distinctly unpleasant shock. It was not uncommon for 20 or more seconds to elapse between shock onset and shock termination. The "activity level" during the $\mathrm{H} 2$ and $\mathrm{H} 4$ group treatment sessions, then, was far greater than that which obtained during typical $\mathrm{Hl}$ and $\mathrm{H} 3$ group sessions.

One consequence of this was a shortening of the interstimulus item intervals for the $\mathrm{H} 2$ and $\mathrm{H} 4$ groups, a situation somewhat analagous to "massed practice." Increased response effort, a result of this "massed practice" effect, as well as heightened tension as a consequence of far greater exposure to shock, led to the $\mathrm{H} 2$ and $\mathrm{H} 4$ group treatment sessions being far more intense and task-oriented. This state of affairs may well have resulted in a buildup of response inhibition during each session, a phenomenon experimentally known to adversely affect resistance to extinction (of, in this case, the newly acquired alternative responses to smoking) (Kimble, 1961). 
Thus, while in theory, the $\mathrm{H} 2$ and $\mathrm{H} 4$ group treatment procedures should have resulted in the systematic positive reinforcement of appropriate non-smoking escape responses, and, therefore, longer lasting smoking behavior suppression, the contaminating effects of reactive inhibition may have attenuated this expected result. Intermittent Reinforcement

Probably the most surprising group performance was that of the random shock (H3) group, a group for which it was predicted there would be no significant mean reduction in smoking, both during the experimental treatment and follow-up phases. Once again, it would appear that the number of stimulus item presentations during the 30-minute session, as well as the frequency of shock onset--for the H3 group, an average of one shock approximately every 45 seconds--were important factors in determining the results obtained by this group. With the occurrence of 40 stimulus item presentations, it was inevitable that many of the shocks were delivered at points in the temporal order which were appropriate for conditioning; i.e., shock onset was of ten contiguous with some aspect of a s's ongoing performance of a motoric or ideational smoking response. At other times, the shock would be delivered after the "optimal" point in the temporal order had passed. Thus, in effect, the $\mathrm{H} 3$ group was in many ways as much a partial reinforcement group as it was a random shock group.

As there is experimental evidence indicating that intermittent negative reinforcement of an operant acquired under essentially positive reinforcement contingencies not only leads to behavior suppression, but also increased resistance to recovery of the suppressed response (Mowrer, 1960), this may explain in part the performance of this group, particularly 
during follow-up. The issue is less clear with respect to the possible effects of delay of (negative) reinforcement, but there is some evidence to indicate that this phenomenon, especially if the delay is variable, increases resistance to recovery over that obtained by immediate punishment alone (Crum, et al., mentioned by Feldman and MacCulloch, 1965). While it is not possible to determine to what extent the effects of intermittent reinforcement, as well as delay of reinforcement, adventitiously increased the mean smoking reduction rate of the $\mathrm{H} 3$ group, the possibility does exist that it may have been considerable.

Respondent Conditioning

It might also be argued, again with the mean smoking performance of the $\mathrm{H} 3$ group primarily in mind, that the internal response states of the $\underline{S}$ came to acquire suppressive properties during the experimental treatment sessions as a function of their contiguity with electric shock onset. These internal respondents, then, elicited in subsequent situations conducive to smoking--or to put it in slightly different terms, in the presence of those CSs which typically would have precipitated smoking behavior--may have served to attenuate a given s's desire to smoke. If such respondent conditioning did in fact occur to a significant degree, this might help explain why the mean smoking reduction rate of the $\mathrm{H} 3$ group in particular, but also for the Hl group, was not significantly different from the mean smoking rates of the other two groups, especially during the follow-up phase. 
It is possible, then, that the variables mentioned in this section, either singularly or in combination, may have caused the net effects of the treatment procedures on the $\underline{S} s$ to be more alike than dissimilar. Such confounding, as a function of the treatment procedures themselves, might explain, at least in part, the absence of significant results obtained in this research. In the next section, several possible contaminating factors, arising from over-all experimental conditions common to all the groups, will be looked at.

\section{Situational Variables as a Source of Confounding}

\section{Interpersonal Effects}

Many behavior therapists have increasingly focused their attention on the issue of the importance of the therapistpatient relationship as a catalyst for behavior change. For example, Barker (1965) talks about the "personal attraction" which may develop towards the therapist, and which "can't be ignored:" Andrews (1966) maintains that behavior therapists, in common with traditionally oriented therapists, are supportive, authoritarian, directive, encouraging, etc., in response to the needs of their individual patients, and that the establishment of satisfactory relationships is mandatory if behavior change is to occur. Feldman and MacCulloch (1965) admitted that their patients "liked to talk" and that they often gave them advice and reassurance. These authors claim that such practices are necessary in order to gain good "background rapport." Coates (1964), and Meyer and Gelder (1963) assert that in all of the conditioning procedures employed to date in 
the clinical literature, the therapist-patient relationship has played a major, if not always recognized, part. And Oswald (1962) has claimed that the success of aversive conditioning, in particular, is vitally dependent upon therapist-patient relationships.

It is perhaps impossible to determine what part relationship variables played in influencing and determining the results of the present study. Koenig and Masters (1965) used seven therapists to treat 42 smokers and found a significant therapist difference $(p<.05)$, but not significant treatment or interactional differences. Thus, the therapist to whom the smoker was randomly assigned, and not the treatment method, was the significant determinant of success with respect to smoking reduction. However, Ober (1967), using three therapists, found no significant treatment, interaction, or therapist effects in his study of smoking behavior. He attributed this lack of a significant therapist main effect to the "highly standardized" treatment procedures his therapists adhered to. Nevertheless, as the smoking reduction scores for the three treatment groups in his study were significantly lower than their pre-treatment levels upon treatment termination, the possibility still remains that relationship effects common to all groups were responsible for this over-all reduction to some significant degree.

With respect to the present study, the attempt was made to minimize E's influence on the mean smoking consumption rates of the experimental treatment groups. For example, not only 
were the treatment presentations standardized, incidental or unnecessary conversation was discouraged, and comments of an evaluative nature concerning the smoking performance of the Ss were withheld. Nevertheless, it may be naive to assume that such attempts alone can effectively control or significantly minimize the $\underline{E}$ influence on $\underline{S}$ performance. It was noticed, e.g., that many of the Ss still appeared to view the treatment session as an occasion for non-task verbal interaction. Such Ss frequently attempted to bring up conversational material of a more personal nature. Others either appeared to want some sort of confirmation that they were progressing satisfactorily, or encouragement from E that they would, in fact, be able to give up cigarets. On occasion, Ss would appear angry, implying by their comments that E was being "unfair" for continuing to shock them despite the fact that they were obviously doing well in their efforts to quit smoking. Examples of "resistance"--the breaking of appointments, arriving late, etc.--were sometimes manifest.

Rosenthal (1966), in his recent book on experimenter effects, discusses an array of situational variables which have been shown to influence research outcome. Of particular relevance for the present study is the one he labels the "acquaintanceship" variable. Since many of the individuals who served as Ss either worked on the same or adjacent wards, or ate in the same lunchroom as $\underline{E}$, the treatment sessions were not the only source of $\underline{E}-\underline{S}$ contact. For these individuals, then, E was more than an anonymous person who "shocked them 
for smoking." He was also an acquaintance and co-worker. Under these circumstances, it is possible that at least some $\underline{\text { Ss }}$ reduced or terminated their cigaret consumption--especially during the treatment phase--either because they didn't want to "disappoint" someone they knew on an individual basis, or because they felt guilty or embarrassed about failing in such a person's presence.

It is also interesting to speculate about the degree to which E's aversive properties were enhanced during the treatment phase of this research. Through repeated association with electric shock, and by virtue of being the person who, insofar as the perception of many of the $\underline{S}$ was concerned, was "trying to get people to stop smoking," $\underline{E}$ may have acquired significant aversive stimulus properties in his own right. In this vein, Rosenthal also points out the tendency for Ss to perceive, either correctly or erroneously, $\underline{E}$ as someone who "expects" them to respond in accordance with their perception of the goals of the experiment. And, as Rosenthal continues, Ss often do just that, primarily for this reason alone. Thus, $\underline{E}$ 's very presence in the hospital setting may have affected the smoking consumption rates of many Ss beyond that which would have obtained from $\underline{E}-\underline{S}$ contact confined only to the treatment room .

Three months after treatment termination, each $\underline{S}$ was informally asked to give any impressions he had about the treatment he had received. Perhaps indicative of the importance of the relationship effect was the observation offered by al- 
most every $\underline{s}$ that $\underline{E}^{\prime} s$ presence in the treatment situation was an extremely important source of smoking behavior influence. Many Ss reported, in fact, that this influence continued after treatment termination. On the other hand, approximately 80 per cent of the $\underline{S} s$ either denied or downgraded the importance of shock, per se, as being a major factor in their reduction or cessation of smoking. Perhaps an example from Goldiamond's (1965) review of stuttering and fluency research is most apropos at this point. Goldiamond mentions one $\underline{S}$ who completely denied that the occurrence or non-occurrence of shock during the experimental period had anything to do with his non-fluency rates, even though the data clearly indicated that the $\underline{s}^{\prime} s$ verbal behavior had been under direct control of the reinforcement contingencies. Nevertheless, while it is perfectly plausable to suspect that the $\underline{S}$ s in the present study were either unaware of, or felt the need to deny, the effect shock had on their smoking behavior, it is an interesting fact that the major focus of their comments was on the interpersonal aspects of the experimental situation.

\section{Subject Motivation}

In all likelihood, $\underline{S}$ motivation represents a variable complex whose effects on performance and treatment outcome are only incompletely understood and poorly controlled (Meyer and Crisp, 1966). A number of writers have discussed the importance of positive initial attitudes towards therapy and strong motivation to change, with respect to the ultimate outcome (e.g., Lazarus, 1963; Meyer and Gelder, 1963). The Ss used 
in this study all appeared, at least initially, to be well motivated. All were voluntary participants, professed the strong desire to give up smoking, and had one or more personally significant reasons underlying their desire to give up cigarets. Yet, motivation was often observed to fluctuate during the course of the study in ways which may have introduced important changes into the experimental situation.

The most common $\underline{S}$ reaction observed by $\underline{E}$ after the sessions had gotten under way, was the emergence of ambivalence-"second thoughts" about giving up cigarets "at this time." Some Ss seemed dismayed that the task of giving up cigarets might require effort and hard work on their part; i.e., that there was no "magic" involved. Others seemed to realize, the closer they came to the goal, the extent to which they had become dependent upon cigarets. At least five or six $\underline{S}$ expressed great concern about failing; i.e., not being able to quit after committing themselves to spouses, relatives, or friends. Perhaps the most interesting reaction noted was the tendency for many of the $\underline{S}$ s across groups to become "unhappy" with the course of treatment, especially around the 7 th, $8 \mathrm{th}$, or 9 th session. This was particularly pronounced if, by that time, a given S's cigaret consumption rate had declined sharply. Such Ss often attempted to negotiate new terms with $\underline{E}$, the goal being to attenuate the original agreement to meet for the full sequence of 15 sessions on a daily basis.

It was primarily for this reason that the $\mathrm{H} 4$ group was begun. It was felt that if $\underline{S}$ could control, in part, the amount of punishment they received, their motivation to terminate 
smoking more quickly would be strengthened. The reward value of avoiding a shock session on the day immediately following one free from smoking, it was further felt, would provide the Ss with sufficient incentive to continue abstaining from smoking on the day that the session was being avoided. It was hypothesized, then, that after such $\underline{\mathrm{S}} \mathrm{s}$ had been able to avoid getting shocked for several days as a consequence of successfully abstaining from smoking, their ability to continue not smoking after treatment termination would be correspondingly greater than that evidenced by the H1, H2, and $\mathrm{H} 3$ group $\underline{S}$. As the $H 4$ group mean cigaret consumption rate during this period was not significantly different from those of the other three groups, it is obvious that the above contention was not supported.

Perhaps the punishment value of the shock sessions themselves may have been over-estimated. If so, then it might be logical to assume the following: that the amount of positive reinforcenent obtained through shock session avoidance was not sufficient to establish inhibitory or self. controlling mechanisms powerful enough to overcome the urge to smoke, once the threat of punishment (attending shock sessions) was removed. On the other hand, it is also possible that the differential effects imputed to the H4 group procedure--and to the other group procedures as well--may have been viable and operating as hypothesized。 However, ihese experimental effects, though present, may have been overshadowed by more potent si.tuational variables common to all the groups. 
In short, much of the smoking reduction or cessation evidenced by all groups during the experimental treatment phase of this study may have been induced by interpersonal or relationship considerations mentioned in this section. It should be pointed out that even the H4 group $\underline{S}$, who attended an average of only 8.6 shock sessions over the three-week experimental period, received daily $\underline{E}$ contact whether they successfully avoided a session or not. And, insofar as follow-up performance is concerned, motivational factors (i.e., ambivalence about really giving up cigarets, possible feelings of dependency and loss, etc.) may have accounted, at least in part, for the degree of smoking recovery evidenced by all the groups. In the next section, some considerations for future research bearing on the points mentioned in this chapter will be discussed.

\section{Some Issues for Future Research}

If the major questions posed by the findings of this study are to be resolved in a satisfactory manner, several issues will have to be considered and dealt with in subsequent investigations. Before proceeding, one point should be made clear. Even though the smoking reduction rates obtained in this study compare quite favorably with the results of other smoking investigations reviewed earlier in the Introduction chapter, the major concern of this research is not smoking reduction or cessation, per se. The major issues are (1) whether treatment procedures based upon an active escape 
conditioning model are any more effective in suppressing unwanted or maladaptive behavior than those based upon simple punishment models, and (2) what the effects of random negative reinforcement are on the performance rates of such behaviors. As this chapter's discussion clearly suggests, before the differential effects of various treatment procedures can be successfully compared, they must first be demonstrated in practice. Therefore, to the degree that it is possible, potential sources of confounding pointed out in the preceding pages must be controlled or removed from future experimental situations. Perhaps the first possible source of confounding that should be dealt with is the relationship variable complex.

It is apparent from the present research that $\underline{E}$ effects on $\underline{S}$ performance must be minimized. A step towards this end would be to use Es who are not known to the Ss. Certainly Es should not be co-workers, or have contact with $\underline{S}$ beyond that which is actually necessary during the treatment sessions themselves. An even better solution might be the removal of E from the immediate stimulus environment while Ss are being run. Stimulus item presentations could be programmed through the use of tape recorders, projectors, or written instructions, and shock could be delivered remotely through the use of one-way mirrors or automatic devices. The .use of "blind" Es -- those who do not know to which group a given $\underline{S}$ has been assigned -- is also indicated. And, to the degree that $\underline{E}-\underline{S}$ contact is necessary, multiple Es could be utilized for each $\underline{\text {. }}$. 
The treatment procedures themselves should be tightened so that the contaminating effects of, e.g., reactive inhibition, partial reinforcement, or delay of reinforcement are not introduced. Towards this end, optimal interstimulus item intervals, as well as the optimal number of stimulus item presentations during each session, should be determined. With respect to the number of treatment sessions actually needed, it will be recalled that the results cited earlier indicated that further reduction in smoking for the $\mathrm{H} 1$, $\mathrm{H} 2$, and $\mathrm{H} 3$ groups was not significant beyond the eighth session-day. Perhaps if fewer shock sessions, and/or a shorter experimental treatment period had been incorporated in to the present research design, some of the resistance evidenced by many of the $\underline{S}$ would have been circumvented.

Changes in the escape paradigm used in the present study might also be considered in subsequent investigations. Solomon (1964), among others, has pointed out that active escape procedures are most effective when they eventually lead to stable avoidance responding. For methodological considerations--primarily, to insure that all Ss received the same number of shock onsets during each treatment session--the H2 group Ss could only terminate the shocks, not avoid them. Perhaps the differential effects of the H2 group (escape) procedure would have been more pronounced, then, if active avoidance responding had been allowed to develop.

Finally, the findings and observations of the present study point up the need for incorporation of a non-shock control 
group in future research attempts. The considerations of $\underline{S}$ availability and time precluded the inclusion of such a group here. Additionally, it was thought that the random shock group would serve the same function. The results obtained from a non-shock group would establish a more meaningful base from which to compare the results obtained from the groups utilizing shock. Most importantly, however, the results of such a group might be most illuminating insofar as the issue of the importance of relationship and motivational variables for behavior change is concerned. 


\section{CHAPTER V}

\section{SUMMARY}

In the majority of the published clinical aversive conditioning studies, the treatment procedures have been based upon a simple punishment model. That is, a short-duration aversive stimulus (usually electric shock) has either been paired with appropriate CSs, and/or the target behaviors themselves. The experimental learning and conditioning literature, however, has indicated that increased and longer lasting behavior suppression would occur when procedures based upon an escape paradigm are used. In addition, experimental findings have also shown that aversive stimuli, randomly administered, have little, if any, lasting suppressive effects on specific ongoing behaviors. Since a comparison of the differential suppressive effects of procedures based upon simple purishment, escape, and random reinforcement paradigms has not been made to date under clinical conditions, this study attemped to do so.

The target behavior used was cigaret smoking, and the aversive stimulus was electric shock. Thirty-two volunteers who wished to stop smoking served as $\underline{s}$ during the course of this investigation. All were between the ages of 25 and 49 , smoked between one and two and a half packs of cigarets per day, 
and had been continuous smokers for at least four years prior to their participation as $\underline{S}$.

Initially, three experimental treatment groups based upon the above mentioned paradigms were begun. Eight $\underline{S}$ s were randomly assigned to each as they became available. All Ss attended 15 individual treatment sessions on a daily basis (omitting weekends), and all received the same number of stimulus item presentations and shock onsets during each session. After the data collection phase had gotten under way, a fourth (session-avoidance) group, whose Ss could miss a scheduled shock session on any day immediately following a day free of smoking, was initiated.

Both motoric and ideational type stimulus items related to smoking behavior were used. The number of cigarets smoked during each of the treatment session-days was recorded for each S. Individual cigaret consumption scores were also collected two, six, and 12 weeks after treatment termination. The hypotheses predicted that the significantly largest mean smoking reduction rate during both the treatment and follow-up phases would be attained by the session-avoidance group. This was to be followed, in decreasing order of procedural effectiveness, hy mean smoking reduction rates of the escape, simple punishment, and finally random shock groups. It was additionally predicted that the session-avoidance, escape, and simple punishment group mean consumption rates on the last session-day, and two, six; and 12 weeks after treat- 
ment termination, would be significantly lower than their respective pre-treatment levels.

The results clearly showed that, in contradiction to the hypotheses, the mean smoking reduction rates of the four groups did not differ significantly from each other during either the experimental treatment or follow-up periods. In other words, each group procedure was essentially as effective as any other in suppressing smoking behavior. Also, the mean smoking reduction scores of all the groups on the last sessionday, and two, six, and 12 weeks after treatment termination, were significantly lower than their pre-treatment levels. The over-all smoking recovery trend evidenced during the followup period was, however, pronounced.

While evidence suggested that uncontrolled variables common to all four treatment groups were operating to effect an over-all reduction in smoking, differential effects of the treatment procedures themselves were not demonstrated.

It was hypothesized that the possible confounding effects of reactive inhibition, intermittent reinforcement, and adventitious respondent conditioning, which may have been introduced by the procedures themselves, as well as relationship and motivational factors, combined to effect the obtained results. 


\section{APPENDICES}


APPENDIX A

TABLE 9

ANALYSIS OF VARIANCE OF AGE--GROUPS H1, H2, H3, AND H4 $\mathrm{N}=32$

\begin{tabular}{lcccc}
\hline \hline Source of Variation & df & Mean Squares & F & P \\
\hline Age, Between Groups & 3 & 51.67 & $<1.00$ & - \\
Age, Within Groups & 28 & 76.71 & \\
\hline
\end{tabular}

TABLE 10

ANALYSIS OF VARIANCE OF THE PRE-TREATMENT MEAN NUMBER

OF CIGARETS SMOKED PER DAY--GROUPS H1, H2, H3, AND H4

$N=32$

\begin{tabular}{lcccc}
\hline Source of Variation & df & Mean Squares & $F$ & $P$ \\
\hline $\begin{array}{l}\text { Cigarets per Day, } \\
\text { Between Groups }\end{array}$ & 3 & 17.67 & $<1.00$ \\
$\begin{array}{l}\text { Cigarets per Day, } \\
\text { Within Groups }\end{array}$ & 28 & 51.71 \\
\hline
\end{tabular}

TABLE 11

ANALYSIS OF VARIANCE OF THE NUMBER OF YEARS A

CIGARET SMOKER--GROUPS H1, H2, H3, AND H4

$\mathrm{N}=32$

\begin{tabular}{lcccc}
\hline \hline Source of Variation & df & Mean Squares & F & P \\
\hline $\begin{array}{l}\text { Years Smoked, Between } \\
\text { Groups }\end{array}$ & 3 & 7.67 & $<1.00$ \\
$\begin{array}{l}\text { Years Smoked, Within } \\
\text { Groups }\end{array}$ & 28 & 62.25
\end{tabular}


ન્ન

mํํ윰ำm유

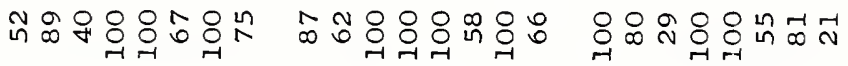

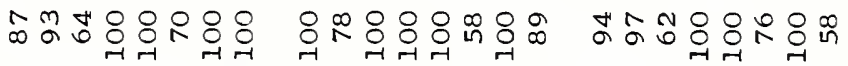
ద

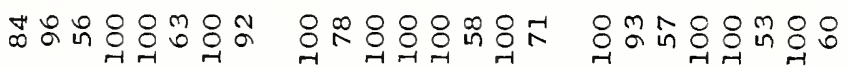

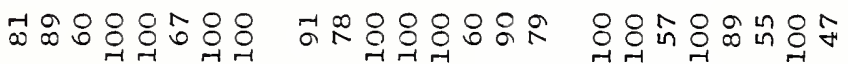

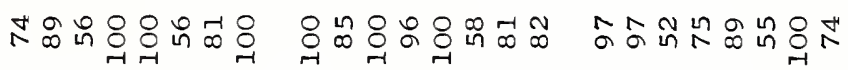

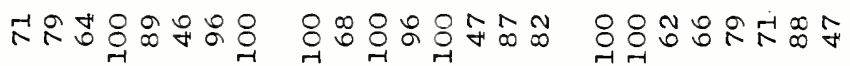

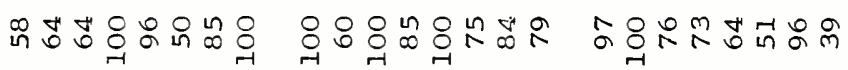

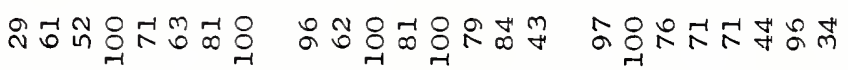
กै in N

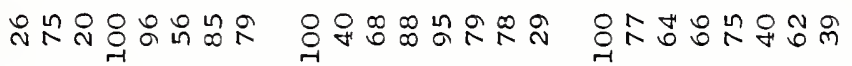

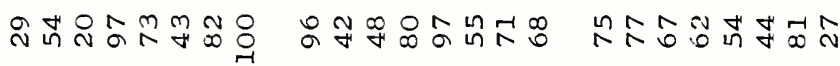

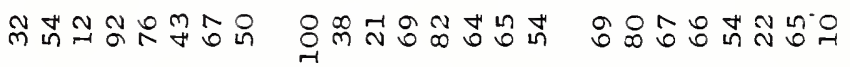
○ 에 각ำ 윳ำ HNM dnoxo IH dnoxo $2 \mathrm{H}$ dnoxs $\varepsilon H$ 


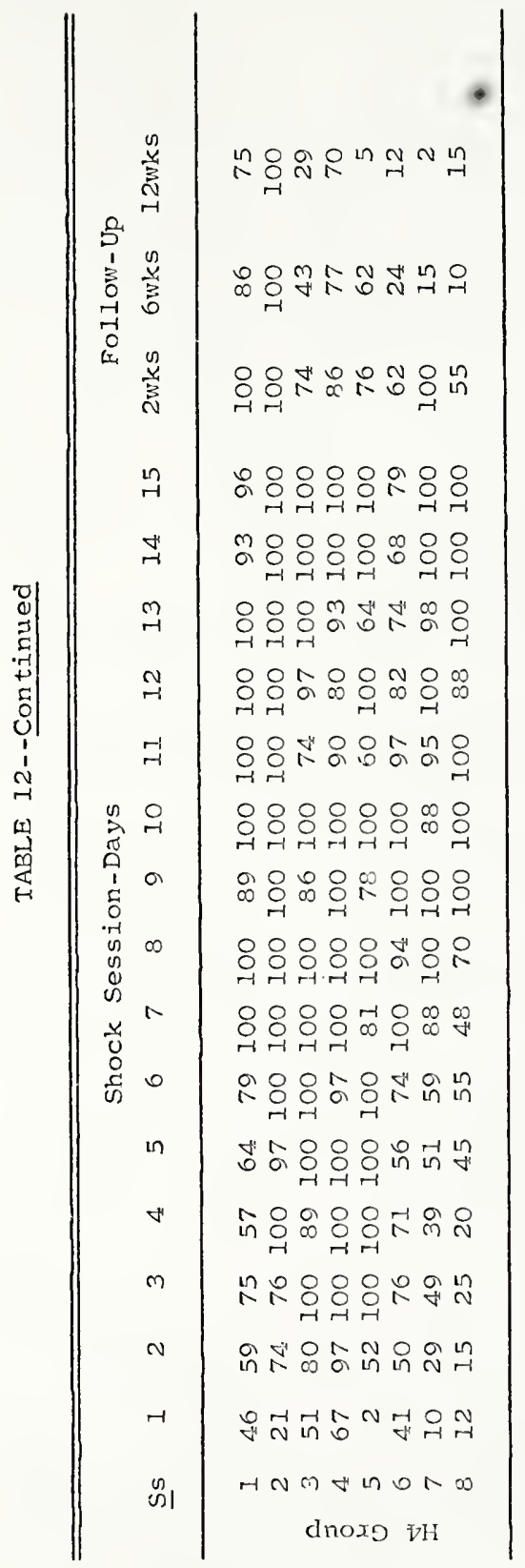




\section{APPENDIX C}

TABLE 13

THREE-DAY MEANS FOR EACH S COMPILED FROM THE ACTUAL NUMBERS OF CIGARETS SMOKED BEFORE TREATMENT AND AT THE END OF FOLLOW-UP

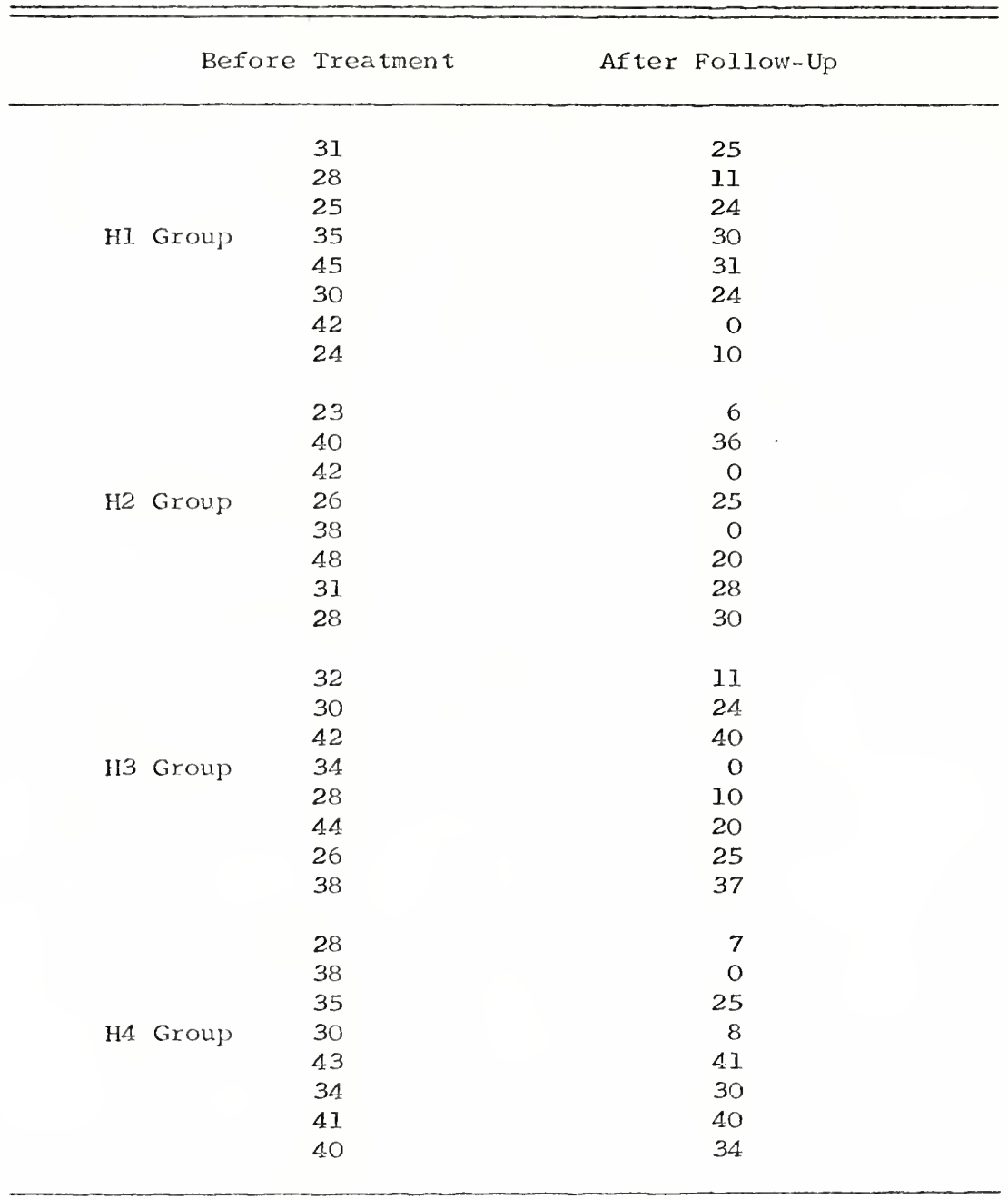




\section{REFERENCES}

Andrews, J. D. Psychotherapy of phobias. Psychol. Buli., $1966, \underline{66}, 455-480$.

Azrin, N. H. Punishment and recovery during fixed-ratio performance. J. exp. Anal. Behav., 1959, 2, 301-305.

Azrin, N. H. Effects of punishment intensity during variableinterval reinforcement. J. exp. Anal. Behav., 1960, 3, 123-142.

Bancroft, J. H., Jones, H. G., and Pullan, B. R. A simple transcucer for measuring penile erection, with comments on its use in the treatment of sexual disorders. Behav. Res. Ther., 1966, 4, 239-241.

Bandura, A. Punishment revisited. J. consult. Psychol., 1962, 26, $298-301$.

Barker, J. C. Behavior therapy for transvestism: A comparison of pharmacological and electric aversion techniques. Brit. J. Psychiat., 1965, 111, 268-276.

Barker, J. C., Thorpe, J. G., Blackmore, C. B., Lavin, N. I., and Conway, C. G. Behavior therapy in a case of transvestism. Lancet, 1961, 1, 510.

Blake, B. G. The application of behavior therapy to the treatment of alcoholism. Behav. Res. Ther., 1965, 3, $75-85$.

Blake, G. A follow-up of alcoholics treated by behavior therapy. Behav. Res. Ther., 1967, ㄴ, 89-94.

Brady, J. V. Ulcers in "executive monkeys." Scient. Amer., $1958, \underline{199}$, 95-103.

British Tuberculosis Association, Smoking deterrent study. Brit. med. J., 1963, 2, 460-487.

Brown, J. S., Martin, R. C., and Morrow, M. W. Self-punitive behavior in the rat: Facilitative effects of punishment on resistance to extinction. J. comp. physiol. Psychol., 1964, 57, 127-133. 
Church, R. M. The varied effects of punishment on behavior. Psychol. Rev., 1963, 70, 369-402.

Clark, D. F. Fetishism treated by negative conditioning. Brit. J. Psychiat., 1963, 109, 404-407.

Coates, S. Clinical psychology in sexual deviation. In I. Rosen (Ed.), The pathology and treatment of sexual deviation, a methodological approach. London: Oxford University Press, 1964.

Cooper, A. J. A case of fetishism and impotence treated by behavior therapy. Brit. J. Psychiat., 1963, 109, 649652.

Estes, W. K. An experimental study of punishment. Psychol. Monogr., 1944, 57 (3, Whole No. 263).

Eysenck, H. J. Behavior therapy, extinction and relapse in neurosis. Brit. J. Psychiat., 1963, 109, 12-18.

Eysenck, H. J., and Rachman, S. Causes and cures of neurosis. San Diego, Calif.: Robert Knapp, 1965.

Feldman, M. P. Aversion therapy for sexual deviations. Psychol. Bu11., 1966, 65, 56-79.

Feldman, M. P., and MacCulloch, M. J. The application of anticipatory avoidance learning to the treatment of homosexuality. Behav. Res. Ther., 1965, 2, 165-183.

Fine, B. J., Marchesani, M., and Sweeney, D. R. A bibliography on the psychological aspects of smoking: January 1940 through September 1965. Psychol. Rep., 1966, 18, 783787.

Franks, C. M. Alcohol, alcoholism, and conditioning. J.ment. Sci., $1958, \underline{104}, 14-33$.

Franks, C. M. Behavior therapy, the principles of conditioning, and the treatment of the alcoholic. Quart. J. stud. Alc., 1963, 24, 511-529.

Franks, C. M. Conditioning techniques in clinical practice and research. New York: Springer, 1964.

Franks, C. M., Fried, R., and Ashem, B. An improved apparatus for the aversive conditioning of cigaret smokers. Behav. Res. Ther., 1966, 4, 301-308.

Gantt, W. H. Experimental basis for neurotic behavior. New York: Hoeber, 1944. 
Goldiamond, I. Stuttering and fluency as manipulatable operant response classes. In L. Krasner and L. P. Ul Imann (Eds.), Research in behavior modification. New York: Holt, Rinehart and Winston, 1965.

Goodman, L. S., and Gilman, A. The pharmacological basis of therapeutics. N. York: Macmillan, 1960.

Greene, R. J. Modification of smoking behavior by free operant conditioning methods. Psychol. Rec., 1964, 14, 171-178.

Hammond, E. C., and Percy, C. Ex-smokers。 N. Y. State J. Med., 1958 (Sept.), 2956-2959.

Holz, W., and Azrin, N. H. Discriminative properties of punishment. J. exp.Anal. Behav., 1961, 4, 225-232.

Holz, W., and Azrin, N. H. Interactions between the discrininative and aversive properties of punishment. J. exp. Anal. Behav., 1962, 5, 225-232.

Hsu, J. J. Electroconditioning therapy of alcoholism. Quart. J. Stud. Alc., 1965, 26, 449-459.

Hul1, C. L. Essentials of behavior. New Haven: Yale University Press, 1951.

Karsh, E. Effects of number of rewarded trials and intensity of punishment on running speed. J. comp. physiol. Psychol., 1962, 55, 44-51.

Kimble, G. A。 Hilgard and Marquis conditioning and learning. New York: Appleton-Century-Crofts, 1961.

Koenig, K. P., and Masters, J. Experimental treatment of habitual smoking. Behav. Res. Ther., 1965, 3, 235-243.

Kushner, M. The reduction of a long-standing fetish by means of aversive conditioning. In L. P. Ullmann and L. Krasner (Eds), Case studies in behavior modification. New York: Holt, Rineharl and Winston, 1965.

Kushner, M. and Sandler, J. Aversion therapy and the concept of punishment. Behav. Res. Ther., 1966, 4, 179-186.

Lazarus, A. A. The results of behavior therapy in 126 cases of severe neurosis. Behav. Res. Ther., 1963, 1, 69-79.

MacCulloch, M. J., Feldman, M. P., Orford, J. F., and Macculloch, M. L. Anticipatory avoidance learning in the treatment of alcoholism: A record of therapeutic failure. Behav. Res. Ther., 1966, 足, 187-196. 
Maier, N. R. F. Frustration: The study of behavior without a goal. New York: McGraw-Hill, 1949.

Martin, B. Reward and punishment associated with the same goal response: A factor in the learning of motives. Psychol. Bull., 1963, 60, 441-451.

Martin, B., and Ross, L. E. Consumatory response punishment. J. comp. physiol. Psychol. , 1964, 58, 243-247.

Masserman, J. M. Behavior and neurosis. Chicago: University of Chicago Press, 1943.

Masserman, $J_{c}$ M., and Pectel, C. Neurosis in monkeys: A preliminary report of experimental observations. Ann. N. Y.Acad. Sci., 1953, 56, 253-265.

Mattexazzo, J. D., and Saslow, G. Psychological and related characteristics of smokers and nonsmokers. Psychol. Bu11., 1960, 57, 493-513.

McGuire, R. J., and Vallance, M. Aversion therapy by electric shock. Brit. med. J., 1964, I, 151-153.

McNamaxa, H. J., and Wike, E. L. The effects of irregular learning conditions upon the rate and permanence of learning. J. comp.physiol. Psychol., 1958, 51, 363-366.

Mees, H. L. Sadistic fantasies modified by aversive conditioning and substitution: A case study. Behav. Res. Ther., 1966,4 , 317-320.

Meyer, V. and Cxisp, A. H. Aversion thexapy in two cases of obesity. Behav. Res.Ther., 1964, 2, 143-147.

Meyer, V. and Crisp, A. H. Some problems in behaviox therapy. Brit.J.Psychiai., 1966, 112, 367-381.

Meyer, V., and Gelder, M. G. Behavior therapy and phobic disorders. Brit.J. Psychiat., 1963, 109, 19-28.

Millex, N. E. Learning resistance to pain and fear: Effects of overlearning, exposure, and rewarded exposure in context. J. exp. Psychol., 1960, 60, 137-145.

Mowrex, O. H. Learning theory and behaviox. New York: John Wiley and Sons, 1960 .

Muenzinger, K. F。, Bernstone, A. H., and Richards, L. Motivation in learning: VIII. Equivalent amounts of electric shock for right and wrong responses in a visual discrimination habit. J. comp.physiol. Psychol.1938, 26, 177-186. 
Muenzinger, K. F., and Powloski, R. E. Motivation in learning: X. Comparison of electric shock for correct turns in a corrective and non-corrective situation. J. exp. Psycho1., 1951, 42, 118-124.

Ober, D. C. The modification of smoking behavior. Unpublished doctoral dissertation, University of Illinois, 1967.

Oswald, I. Induction of illusory and hallucinatory voices. J. ment. Sci., 1962, 108, 196-212.

Prince, A. I. Effect of punishment on visual discrimination learning. J. exp. Psychol., 1956, 52, 381-385.

Pyke, S., Agnew, N.M., and Kopperud, J. Modification of an overlearned maladaptive response through a relearning program: A pilot study on smoking. Behav. Res. Ther., 1966,4 , 197-203.

Rachman, S. Aversion therapy: Chemical or electrical? Behav. Res. Ther., 1965, 2, 289-299.

Raymond, M. J. Case of fetishism treated by aversion therapy. Brit. med. J., 1956, 2, 854-857.

Rosenthal, R. Experimenter effects in behavioral research. New York: Appleton-Century-Crofts, 1966.

Sanderson, R. E. An investigation of a new aversive conditioning therapy for alcoholism. Creative talents awards program, Series 3. Washington: American Institute for Research, 1963, 39-43

Sandler, J. Masochism: An empirical analysis. Psychol. BuI1., 1964, 62, 197-204.

Skinner, B. F. Walden two. New York: Macmillan, 1948.

Skinner, B. F. Science and human behavior. New York: Macmillan, 1953.

Smoking and health: Report of the advisory committee to the Surgeon General of the Public Health Service. Washington, D. C.: U. S. Dept. Hlth., Educ. and Welf., 1964. (P. H. S. Publ. No. 1103)

Solomon, R. L. Punishment. Amer. Psychol., 1964, 19, 239-253.

Solomon, R. L., and Wynne, L. C. Traumatic avoidance learning: Acquisition in normal dogs. Psychol. Monogr., 1953, 67, 1-19.

Tate, B. G., and Baroff, G. S. Aversive control of selfinjurious behavior in a psychotic boy. Behav. Res. Ther., 1966, $\underline{4}, 281-287$. 
Thorndike, E. L. Reward and punishment in animal learning. Comp. Psychol. Monogr., 1932, 8 (Whole No. 39 ).

Thorpe, J. G., and Schmidt, E. Therapeutic failure in a case of aversion therapy. Behav. Res. Ther., 1963, 1, 293296.

Thorpe, J. G., Schmidt, E., Brown, P. T., and Castell, D. Aversion-relief therapy: A new method for general application. Behav. Res. Ther., 1964, 2, 71-82.

Thorpe, J. G., Schmidt, E., and Castell, D. A comparison of positive and negative (aversive) conditioning in the treatment of homosexuality. Behav. Res. Ther., 1963, I, 357-362.

Turner, L. H., and Solomon, R. L. Human traumatic avoidance learning: Theory and experiments on the operantrespondent distinction and failures to learn. Psychol. Monogr., 1962, 76 (Whole No. 559).

Wilde, G. J. S. Behavior the rapy for addicted cigarette smokers: A preliminary investigation. Behav. Res. Ther., 1964, 2, 101-109.

Wolpe, J. Conditioned inhibition of craving in drug addiction: A pilot experiment. Behav. Res. Ther., 1965, 2, 285288.

Woodworth, R. S., and Schlosberg, H. Experimental psychology. New York: Holt and Co., 1958. 


\section{BIOGRAPHICAL SKETCH}

Michael Samuel Stokols was born in Chicago, Illinois, on September 11, 1938, and moved to Miami, Florida, with his family at the age of six. He graduated from Miami Senior High School in 1956, attended the University of Florida from September, 1956 to June, 1958, and received the Bachelor of Arts degree with a major in Psychology and minor in Biology from the University of Miami (Florida) in January, 1960. Mr. Stokols entered the Graduate School of the University of South Carolina in February, 1961, and received the Master of Science degree in Psychology from this institution in August, 1962. Since entering the Graduate School of the University of Florida in September, 1962, he has been engaged in fulfilling the requirements for the degree of Doctor of Philosophy in Clinical Psychology.

Mr. Stokols' financial support while at the University of Florida has included an assistantship in the Reading clinic, traineeships through the Department of Vocational Rehabilitation, and participation in the Veterans Adninistration Psychology Assistantship Program. In May, 1967, he completed a predoctoral internship in clinical psychology at the Edvard G. Hines Veterans Adninistration Hospital, Hines, rllinois. Mr. Stokols is presently employed as a clinical Psychologist, Level III, at the Illinois State Pediatric Institute, Chicago, Illinois. 
This dissertation was prepared under the direction of the chairman of the candidate's supervisory committee and has been approved by all members of that committee. It was submitted to the Dean of the College of Arts and Sciences and to the Gradiate Council, and was approved as partial fulfillment of the requirements for the degree of Doctor of Philosophy. December, 1968

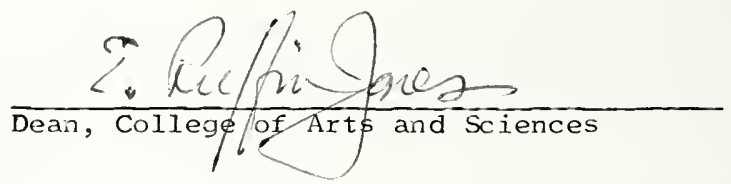

Dean, Graduate School

Supervisory Committee:
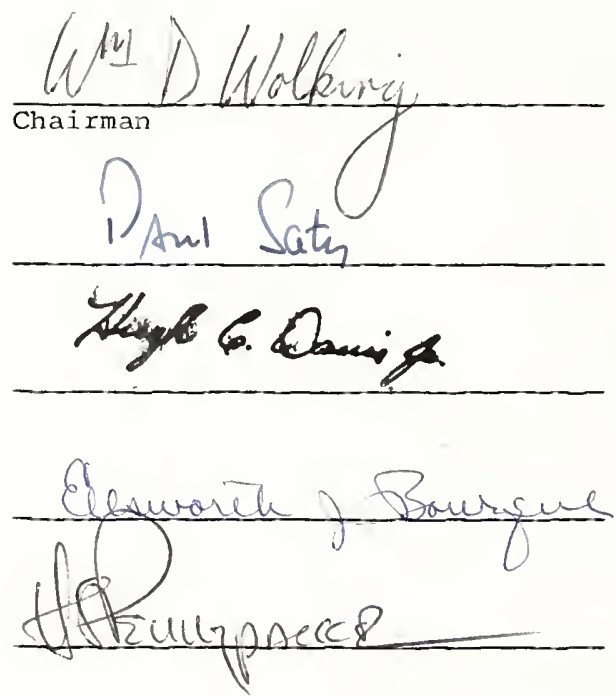